\title{
The evolving role of PARP inhibitors in advanced ovarian cancer
}

Research Article \author{
Marianna K. Pispirigou ${ }^{5}$, Panagiotis Koliou ${ }^{6}$ \\ 'Oncology Department, Bioclinic Private Hospital, Thessaloniki, Greece \\ 'Department of Medical Oncology, Papageorgiou General Hospital, \\ Thessaloniki, Greece \\ ${ }^{3}$ Department of Medical Oncology, Papageorgiou General Hospital, \\ Thessaloniki, Greece \\ ${ }^{4} 1$ st Department of Medical Oncology, Theagenion Hospital, 54007 \\ Thessaloniki, Greece \\ 52nd Department of Medical Oncology, Henry Dunant Hospital Center, 107 \\ Mesogeion Ave, 115 26, Athens, Greece \\ ${ }^{6}$ Marianna K. Pispirigou, MD, Division of Oncology, Department of Internal \\ Medicine, University Hospital of Patras, Greece \\ 'Panagiotis Koliou, BS, MSc, MD, PhD, Royal Surrey NHS Foundation Trust, \\ Guildford, Surrey, United Kingdom
}

Sofia Levva1*, Aglaia Skolariki², Eleni Sogka², Alexandros Bokas³, Avraam Assi4,

Received 2 January 2021; Accepted 18 February 2021

\begin{abstract}
The field of ovarian cancer has been revolutionized with the use of poly (ADP-ribose) polymerase (PARP) inhibitors, which present greater inhibition effect in epithelial subtype due to high rates of homologous recombination deficiency. PARP inhibition exploits this cancer pitfall by disrupting DNA repair, leading to genomic instability and apoptosis. Three PARP inhibitors (olaparib, niraparib, and rucaparib) are now approved for use in women with epithelial ovarian cancer, while others are under development. Among women with BRCA1/2 mutations, maintenance PARP therapy has led to a nearly fourfold prolongation of PFS, while those without BRCA1/2 mutations experience an approximately twofold increase in PFS. Differences in trial design, patient selection and primary analysis population affect the conclusions on PARP inhibitors. Limited OS data have been published and there is also limited experience regarding long-term safety. With regard to toxicity profile, there are no differences in serious adverse events between the experimental and control groups. However, combining adverse event data from maintenance phases, a trend towards more events in the experimental group, compared with controls, has been shown. The mechanisms of PARP-inhibitor resistance include restoration of HR through reversion mutations in HR genes, leading to resumed HR function. Other mechanisms that sustain sufficient DNA repair are discussed as well. PARP inhibitors play a pivotal role in the management of ovarian cancer, affecting the future treatment choices. Defining exactly which patients will benefit from them is a challenge and the need for HRD testing to define 'BRCA-ness' will add additional costs to treatment.
\end{abstract}

Keywords: ovarian cancer $\bullet$ PARP inhibitors $\bullet$ BRCA mutation • maintenance treatment • resistance mechanisms $\bullet$ homologous recombination deficiency

\section{Abbreviations}

PFS

OS

OC

PARPi

DDR

SSBs

HR

DSB

HRD
Progression Free Survival

Overall Suvival

Ovarian Cancer

PARP inhibitor

DNA damage response

single strand brakes

Homologous Recombination

double strand breaks

Homologous Recombination Deficiency

$\begin{array}{ll}\text { LOH } & \text { Loss Of Heterozygosity } \\ \text { HGSOC } & \text { High Grade Serous Ovarian Cancer } \\ \text { EMA } & \text { European Medicines Agency } \\ \text { FDA } & \text { Food and Drug Administration } \\ \text { ORR } & \text { Objective Response Rate } \\ \text { BCS } & \text { Biopharmaceuticals Classification System } \\ \text { VEGFR2 } & \text { Vascular Endothelial Growth Factor } \\ & \text { Receptor 2 } \\ \text { VEGF } & \text { Vascular Endothelial Growth Factor } \\ \text { ORF } & \text { Open reading frame } \\ \text { ABC } & \text { ATP-binding cassette }\end{array}$




\section{AE Adverse event \\ PPI's Proton pump inhibitors \\ MDS/AML Myelodysplastic Syndrome / Acute Myeloid Leukemia}

\section{Background}

Despite recent advances in cancer diagnosis and treatment, ovarian cancer (OC) remains the fifth most common cause of death from cancer in women in the United States and Europe ${ }^{[1,2]}$. This is mainly attributed to the fact that the majority of patients are diagnosed at advanced stage, mainly stage III disease ${ }^{[3]}$. Therefore, effective treatment options at these stages of disease are of urgent need. The clinical application of PARP inhibitors (PARPis) has drastically changed OC therapy during the last decade. Early hints of activities, shown in the first clinical trials, had led to anticipatory excitement for this class of agents. Undeniably, the magnitude of benefit of PARP inhibitor (PARPi) therapy is considerable. However, treatment resistance is inevitable resulting in progress of disease and modest survival benefit ${ }^{[4]}$. Ongoing clinical trials are testing new treatment strategies including new molecules and combination treatments to overcome resistance. Moreover, several PARPis have been approved the last two years, while treatment indications have changed, resulting in a variety of therapeutic options. In this comprehensive review we will discuss all the new available data with regard to the use of PARPis in OC treatment.

\section{Mechanism of action}

Unlike normal cells, cancer cells are characterized by their continuous proliferation, driven either by activation of oncogenic genes or inactivation of tumor suppressor genes, resulting in inadequate repair of DNA replication errors and a higher susceptibility to genomic instability ${ }^{[5,6]}$. The family of poly (ADP-ribose) polymerases (PARPs) consists of at least 18 enzymes, mainly represented by the DNA-binding PARP1 and PARP2, and exerts a multitude of actions, ranging from mediation of cardiac and inflammatory disease to their activity in DNA repair mechanisms ${ }^{[7]}$. PARPs have a central role in the DNA damage response (DDR) system which is comprised of various pathways that contribute to preserving the genome ${ }^{[8]}$. Upon activation by DNA damage, PARP1 binds to loci of single strand brakes (SSBs) and triggers a repair complex by attracting repair proteins and promoting chromatin remodeling, ultimately leading to the repair of DNA lesions $^{[7]}$. This posttranslational process is named PARylation[Poly(ADP-ribosyl)ation] and is mainly activated under stressing conditions ${ }^{[9]}$.

The initially proposed mechanism of action of PARP inhibition was based on the potential synergistic effect of PARPi with chemotherapeutic agents and radiotherapy, which were known to cause DNA damage in cancer cells ${ }^{[6]}$. However, this treatment approach was limited by several factors, including the increased toxicity and difficulty in patient selection and optimal treatment combination ${ }^{[10]}$. Current knowledge of PARPis' mechanism of action is focused on the concept of "synthetic lethality", a term used to describe the effects of PARP inhibition when combined with defective homologous repair (HR) system that was attributed to BRCA1 and BRCA2 mutations ${ }^{[11,12]}$. PARP inhibition results in failure to repair SSBs, which in turn accumulate and ultimately lead to the formation of double strand breaks (DSB); in HR deficient cells DSBs remain unrepaired leading the cells to high genomic instability and death ${ }^{[8]}$. More recent findings show that PARPi have 2 distinct mechanisms of action; they can act as catalytic inhibitors of PARylation, but also promote structural changes and the trapping of PARP1 in a PARP-DNA complex, leading to delays of the SSB repair replication fork and final DSB formation ${ }^{[13]}$.

Clinical trials have revealed that PARP inhibition is effective in wild type BRCA1,2 ovarian cancer cells as well. This has led to the recognition of the pivotal role that the HR system has in DNA damage repair and the inclusion of a number of HR gene deficiencies that predict responsiveness to PARPi (RCC2, XRCC3, RAD54, andH2A) and comprise the BRCAness phenotype ${ }^{[13,14]}$. Further analysis of these BRCA-like ovarian cancers revealed that homologous repair deficiency (HRD) may be attributed to various genomic alterations, mainly loss of heterozygosity (LOH), telomeric allelic imbalance and large-scale transitions. These alterations are considered surrogates that can be combined to provide an assessment of the tumor's HRD score that has emerged as a possible biomarker of sensitivity to PARPis ${ }^{[15,71,76]}$.

The model of a delay in replication fork has recently been challenged by a study, showing that in BRCA1 deficient cells, PARPi actually induces an increase in fork replication speed above a specified threshold, which results in a reduced cell capacity to recognize and repair DNA brakes ${ }^{[16]}$. These data show that PARPis in fact trigger the replication stress that would normally be regulated with PARylation; this in turn leads the tumor cells to replication fork collapse, DNA doublestrand breaks and a proclivity to undergo abnormal DNA synthesis. DNA damage is further accumulated and 
compromises cancer cells' viability ultimately leading to cell death ${ }^{[17]}$.

\section{PARP inhibitors in ovarian cancer}

Up to the present, more than ten PARP inhibitors have been developed and tested, not only for ovarian cancer but also for other solid tumors, BRCA related or not. The first study to confirm efficacy of a PARP inhibitor in germline BRCA mutation carriers was conducted over a decade ago, pointing out the way to a novel therapeutic approach $^{[18]}$. Initially, most trials of PARPi in OC clinical settings, included patients with germline BRCA mutations. Since then, the clinical relevance of PARPis has been confirmed in a number of studies including a larger group of patients, namely patients with somatic $B R C A 1 / 2$ mutations, HRD and genetic or epigenetic aberrations that result in a "BRCAness" profile ${ }^{[19,20]}$. This broad group of patients appears to respond better to platinum-based chemotherapies, as well as to PARPis, ultimately demonstrating improved progression-free and overall survival rates ${ }^{[21-24]}$.

Approximately $15 \%$ of epithelial ovarian carcinomas are known to harbor germline mutations in $B R C A 1 / 2$ genes, while $6 \%$ present $B R C A 1 / 2$ somatic mutations ${ }^{[21}$ ${ }^{23,25]}$. Another $20 \%$ has been associated with a mutation or epigenetic silencing of other genes in the HR pathway, such as ATM, CHEK1, CHEK2, RAD51C, RAD51D, BRIP1, MRE11A and PALB2 ${ }^{[23,25,26]}$. In addition, other epigenetic processes, such as aberrant promoter hypermethylation, lead to significant disruption of this mechanism and can cause genomic instability ${ }^{[27]}$. Another example is the EMSY gene amplification or overexpression, which interferes with BRCA2 protein activity in $20 \%$ of high-grade serous OC (HGSOC) ${ }^{[28-30]}$.

Incidence of germline and somatic mutations in ovarian cancer seems to be histology dependent. Around $50 \%$ of HGSOC exhibit a defect in the HR repair mechanism, whereas low-grade serous carcinomas harbor HR defects less frequently $(3-11 \%)^{[23,25]}$. As far as endometrioid and clear-cell carcinomas is concerned incidence of $\mathrm{HR}$ defects varies widely, ranging between 8-37.6\% and 3-26\% respectively ${ }^{[22,23,31-33]}$. Endometrioid histology, instead, has been strongly associated with Lynch syndrome ${ }^{21,34,35]}$. Even rarer, HR defects can be found in mucinous $\mathrm{OC}$ and carcinosarcomas.

Currently, there is marketing approval in ovarian cancer for olaparib, rucaparib and niraparib. Investigated or under investigation are talazoparib, veliparib, fluzoparib, pamiparib, E7449, IMP4927, NMS-P515, while iniparib (INN, previously known as BSI 201) is no longer considered as a PARP inhibitor.
The basic biochemical characteristics of the most known PARPis are presented in Table $1^{[14,36-45]}$. Although PARPi main target is PARP 1 protein, trapping potency is differentiated among them. The leading position belongs to talazoparib, which differs up to 200 -fold than the others in its capacity to trap its target. Olaparib and rucaparib, almost equivalent to each other, come after, followed by veliparib and niraparib. The potency of catalytic inhibition follows the same rank order but with substantially smaller variance ${ }^{[46]}$. However, both in vitro and in vivo models show, that trapping potency does not correlate with the therapeutic efficacy in monotherapy treatment with PARPi ${ }^{[13,46]}$. Contrariwise, trapping potency plays an important role in clinical outcome and tolerability when these drugs are combined with other agents, most often with alkylating agents ${ }^{[47]}$.

\subsection{Olaparib (AZD2281 or KU-0059436) (Lynparza, Astrazeneca)}

Olaparib is the first polyADP-ribose polymerase inhibitor approved for ovarian cancer both by EMA and FDA in 2014[36]. It blockades in a reversible way PARP$1,-2$ and -3 isoforms of the PARP family enzymes. The trapping of PARP1 is stronger and it constitutes the main mechanism of olaparib cytotoxic activity ${ }^{[13]}$. Olaparib has low aqueous solubility characteristics and no lipophilic compound, which is translated in low membrane permeability. This may not affect the drug absorption but it impedes its penetration in the brain, so that the final tumor tissue exposure is about $60 \%$ less of the plasma concentration ${ }^{[37,38]}$. A fat or high calorie meal may cause delay in drug absorption and peak plasma concentration, but the final bioavailability remains intact, so that patients can receive the drug regardless of food ${ }^{[48]}$. A steady state situation in plasma occurs within 3-5 days of drug initiation and it is almost 0.8 times higher when olaparib is taken as a tablet ${ }^{[49]}$. It is metabolized in the liver, primarily mediated by CYP3A4 and CYP3A5, whilst its metabolites are excreted in feces $(12-60 \%)$ and urine $(35-60 \%)$. A dosage adjustment is necessary in severe liver and renal insufficiency, as well as with concomitant use of a CYP3A inhibitor ${ }^{[48]}$.

Olaparib is available for oral administration, initially only as capsule of $50 \mathrm{mg}$ and now as a tablet of $100 \mathrm{mg}$ and $150 \mathrm{mg}$, as well. The new dose is $300 \mathrm{mg}$ twice daily. The need for another pharmaceutical form arose in an attempt to improve drug bioavailability. As capsules and tablets are not bioequivalent, the one formulation cannot be changed or replaced by the other one in any indication and time of treatment. Since 2017, based on SOLO-2 results, the tablet is the indicated pharmaceutical form 
Table 1: Biochemical Characteristics of PARP inhibitors.

\begin{tabular}{|c|c|c|c|c|c|c|c|c|}
\hline & $\begin{array}{l}\text { Molecular } \\
\text { formula }\end{array}$ & $\begin{array}{c}\text { Molecular } \\
\text { weight } \\
\text { (g/mol) }\end{array}$ & Route & $\begin{array}{l}\text { Peak plasma } \\
\text { concentration }\end{array}$ & Potency & $\begin{array}{c}\mathrm{IC}_{50^{\star}} \\
\text { Nmol } \\
\text { PARP1/2 }\end{array}$ & $\begin{array}{c}\text { Max } \\
\text { tolerated } \\
\text { dose }\end{array}$ & Half-life \\
\hline Olaparib & $\mathrm{C}_{24} \mathrm{H}_{23} \mathrm{FN}_{43}$ & 434.5 & oral & $1-3 \mathrm{hr}$ & $\begin{array}{c}\text { PARP1 > PARP2 } \\
>>\text { PARP3 }\end{array}$ & $5 / 1$ & $\begin{array}{l}\text { Tb 300mg } \\
\text { BID } \\
\text { Cap 400mg } \\
\text { BID }\end{array}$ & $5-11 \mathrm{hr}$ \\
\hline Rucaparib & $\mathrm{C}_{19} \mathrm{H}_{18} \mathrm{FN}_{30}$ & 323.4 & oral & $1.9 \mathrm{hr}$ & $\begin{array}{c}\text { PARP1 > PARP2 } \\
\text { > > PARP3 } \\
\text { And } \\
\text { tankyrase inhibitor }\end{array}$ & 1.4 & $\begin{array}{l}\text { Tb } 600 \mathrm{mg} \\
\text { BID }\end{array}$ & 17-19hr \\
\hline Niraparib & $\mathrm{C}_{19} \mathrm{H}_{20} \mathrm{~N}_{4 \mathrm{O}}$ & 320.4 & oral & $3 \mathrm{hr}$ & PARP1 = PARP2 & $3.2 / 4$ & $\begin{array}{l}\text { 300mg once } \\
\text { daily }\end{array}$ & $36 \mathrm{hr}$ \\
\hline Veliparib & $\mathrm{C}_{13} \mathrm{H}_{16} \mathrm{~N}_{40}$ & 244.29 & oral & $0.5-1.5 h r$ & PARP1 PARP2 & $5.2 / 2.9$ & $\begin{array}{c}\text { Tb } 400 \mathrm{mg} \\
\text { BID }\end{array}$ & $5.2 \mathrm{hr}$ \\
\hline Talazoparib & $\mathrm{C}_{19} \mathrm{H}_{14} \mathrm{~F}_{2} \mathrm{~N}_{6 \mathrm{O}}$ & 380.4 & oral & $1-2 \mathrm{hr}$ & & $1.2 / 0.9$ & $\begin{array}{l}\text { Cap 1mg } \\
\text { daily }\end{array}$ & $90 \mathrm{hr}$ \\
\hline
\end{tabular}

*IC50: half maximal inhibitory concentration $\quad{ }^{\circ}$ BID: bis in die, twice daily

for every clinical practice ${ }^{[36,50]}$. In fact, all phase III trials published, used the tablet formulation and FDA has permanently discontinued the capsule since 2018.

The efficacy and safety of olaparib in patients with germline BRCA1/2 mutations and recurrent ovarian cancer have been assessed in a number of trials, both in platinum resistant disease in comparison with chemotherapy, and in platinum sensitive disease as maintenance treatment ${ }^{[14,51-54]}$. Olaparib was initially granted FDA approval as monotherapy for patients with advanced OC and germline BRCA mutations, who had been previously treated with three or more chemotherapy regimens, following the results of a phase 2 study ${ }^{[55,56]}$. Benefit from olaparib monotherapy in terms of tumor objective response rate (ORR) (31.1\%), duration of response (median, 225 days), PFS (median, 7 months) and OS (median, 16.6 months) was reported. Differences regarding the RR between BRCA1 and $B R C A 2$ mutation carriers were not considered of note ${ }^{[55}$, 56].

The first indication of PARPi efficacy in OC patients without germline BRCA mutations was introduced after a multicenter, phase 2 trial, in patients with advanced, high-grade serous or poorly differentiated OC, as well as breast cancer ${ }^{[57]}$. Objective responses were observed in all women with $\mathrm{HGSOC}$, both with and without $B R C A$ mutations, particularly in those with platinum-sensitive carcinomas, supporting the hypothesis that factors implicated in the HR repair mechanism, besides germline $B R C A$ mutations, may predict sensitivity to PARPi treatment. Furthermore, the reported data of Study 19, confirmed PFS benefit in women with platinum-sensitive HGSOC and suggested that further investigation is required regarding the efficacy of PARPi in women with BRCAness phenotype ${ }^{[14]}$. The prearranged analysis according to BRCA status indicated that the origin of BRCA mutations was not associated with the response to PARPi treatment, as women with somatic BRCA mutations gained similar benefit ${ }^{[53]}$. A further updated analysis of these patients revealed statistically significant improvement regarding PFS (HR 0.23) and OS (HR 0.15) $)^{[58]}$.

Since then, more robust evidence for the efficacy of olaparib has been aggregated from phase 3 trials in various treatment settings. SOLO2 was designed to determine the efficacy of olaparib versus placebo, as maintenance therapy in platinum-sensitive, relapsed, BRCA-associated OC patients ${ }^{[50]}$. Germline BRCA mutations were confirmed in all patients and deemed pathogenic or likely pathogenic in $97 \%$ of cases. Maintenance olaparib extended median PFS by 13.6 months with an HR of 0.30 . Furthermore, improvement was observed regarding time to first subsequent therapy (median, 27.9 vs 7.1 months), time to second subsequent therapy (HR 0.37), as well as time to second progression or death (HR 0.50). As a result, the indications were expanded by both the FDA and the EMA in the maintenance therapy setting, to include relapsed OC patients, with response to previous platinum-based chemotherapy, irrespective of their BRCA status ${ }^{[45,59]}$. Very recently, final impressive overall survival data was announced, with a median OS improvement of nearly 13 months $^{[60]}$. Regarding first-line maintenance therapy, the results of the SOLO1, confirmed the efficacy of olaparib in this additional setting ${ }^{[61]}$. The vast majority of participants was germline BRCA mutant (388/391 patients); two patients had somatic BRCA mutations and one had a BRCA variant of uncertain significance. Olaparib maintenance offered 36 months median PFS benefit, compared to placebo. Similar significant 
improvements were observed in time to first subsequent therapy and time to second disease progression, while OS did not appear to differ substantially at that point. Safety profile was as expected.

SOLO3 trial tested whether olaparib was more effective than physician-selected chemotherapy in women with germline BRCA-associated, platinumsensitive, relapsed HGSOC treated with at least 2 prior platinum-based chemotherapy lines. ORR proved to be significantly higher $(72.2 \%$ vs $51.4 \%)$ and PFS was further improved in favor of the olaparib group (median, 13.4 vs 9.2 months) ${ }^{[62]}$. The clinical relevance of these findings remains debatable, since at present most of the patients receive olaparib as first-line maintenance therapy. Until new evidence surfaces regarding the role of olaparib in heavily pretreated patients, including PARPi as prior therapy, this question stands unanswered. On the other hand, olaparib monotherapy may be more relevant in patients with relapsed, platinum-resistant OC, as it is indicated by the preliminary results of the ongoing CLIO trial[63]. ORR for olaparib monotherapy proved superior against standard-of-care chemotherapy (18\% vs $6 \%$, respectively), especially in patients with germline mutations. Further analyses of patients with somatic BRCA mutations are ongoing. Finally, the efficacy of olaparib has been tested in combination with other antitumor agents, which is discussed in another section.

\subsection{Rucaparib (AG-14447) (Rubraca, Clovis Oncology)}

Rucaparib is a small molecule inhibitor of PARP-1, -2 and -3 and of tankyrase- 1 and -2 . It is considered the less selective PARPi and its strongest trapping target is PARP-1. It's efficacy is increased by blockading both PARPs and hexose-6-phosphate dehydrogenase (H6PD) ${ }^{[64]}$. Rucaparib's full name is rucaparib camsylate and it belongs to camphorsulfonate salts. Its water solubility is low, irrespective of the $\mathrm{pH}$ range, while its permeability is low- to moderate ${ }^{[45]}$. Rucaparib was tested both intravenously and orally, whereas oral rucaparib achieved better results with regard to ORR and disease stabilization ${ }^{[65]}$. It is available as an oral tablet and can be administered with or without food, though there is a moderate effect of food in the drug pharmacokinetics ${ }^{[66]}$. Its average bioavailability is $36 \%$ and the maximum concentration is reached in 1.9 hours. Rucabarib succeeds a steady state in 1 week following the indicated dose of $600 \mathrm{mg}$ twice daily ${ }^{[39,66]}$. The drug is metabolized in liver via oxidation and glucuronidation, primarily by CYP2D6 and to a lesser extent by CYP1A2 and CYP3A4. The major metabolite is named M324 and it is inactive. The drug is excreted both intact and through its metabolites through feces $(>72 \%)$ and urine $(\sim 17 \%)$. In cases of mild to moderate renal disease or in mild liver insufficiency no dose adjustments are required. There are no data for more severe impairments ${ }^{[39,45]}$. Rucaparib distribution in the brain is limited and this is potentially due to its interaction with p-glycoproteins, implying a drug resistance mechanism ${ }^{[67,68]}$. Regarding interactions with other drugs, two factors should be taken under consideration when rucaparib is administered: first that rucaparib inhibits p-glycoproteins and second its relationship with the CYP-enzymes.

Rucaparib, has shown acceptable toxicity profile and antitumor activity in patients with germline and somatic BRCA mutations and HRD ${ }^{[69-72]}$. ARIEL2 was designed to determine whether rucaparib would maintain its efficacy across three subgroups of women with platinum-sensitive, relapsed HGSOC, based on BRCA mutation status and LOH; BRCA mutant, BRCA wild-type with high $\mathrm{LOH}$ and BRCA wild-type with low $\mathrm{LOH}^{[71]}$. PFS was significantly improved in women with BRCA mutations as compared to the other subgroups, irrespective of mutation's origin (germline or somatic) [71, 72]. Proceeding to the maintenance clinical setting, ARIEL3 recruited 564 patients with platinum-sensitive, recurrent HGSOC, with complete or partial response to their previous platinum-based therapy. PFS advantage was consistent across all prespecified subgroups, regardless of parameters such as $\mathrm{LOH}$, BRCA status, disease at baseline or response to previous treatment. With regard to the HRD cohort, significant PFS prolongation was also noted for the patients on rucaparib and this overall benefit was consistent, regardless of the presence of BRCA mutations ${ }^{[73]}$. However, the presence of mutations in other HR genes, both in $\mathrm{LOH}$ high and low subgroups, suggests that more sensitive biomarkers, predictive of the PARPis response, are required. Based on the results of Study 10, ARIEL2 and ARIEL3, rucaparib, initially approved by the FDA in 2016 for advanced high grade serous ovarian cancer with germline $B R C A$ mutations as a third or later line treatment, was also approved in 2018 by the FDA as a maintenance treatment for the platinum sensitive disease irrespective of BRCA status ${ }^{[71,73]}$. With regard to maintenance treatment setting, its role is going to be elucidated by the MAMOC trial (NCT04227522), which is going to be initiated soon. Patients will be randomized to receive rucaparib vs. placebo, until disease progression and/or death, or unacceptable toxicity, after receiving bevacizumab maintenance for 12 to 15 months. 


\subsection{Niraparib (MK-4827) (Zejula, GlaxoSmithKline)}

Niraparib is the first PARPi to show PFS benefit as maintenance treatment in both BRCA mutant and wild type women with platinum sensitive recurrent OC. It equally and selectively blockades PARP-1 and -2, which is a common characteristic with veliparib. They are both carboxamides, so their carboxyl terminal domain interacts via hydrogen bonds with the a-helical domain of the PARP-1 and -2 enzymes, a subdomain which does not exist in other PARPis ${ }^{[40]}$. Niraparib has a crystal structure and is classified according to $\mathrm{BCS}$ as class II. Its solubility is independent of the $\mathrm{pH}$ conditions. It is disposable only as capsule of $100 \mathrm{mg}$ and the standard dose of any clinically relevant indication is $300 \mathrm{mg}$ once daily. Niraparib is very rapidly absorbed irrespective of time or quality of meals intervals, having a bioavailability of $73 \%$ in humans, and reaching the peak plasma concentration in about 3 hours. Due to its high membrane permeability, it can cross the bloodcerebrospinal barrier, leading to brain concentration of 0.9 -fold the concentration in plasma. Regarding tumor exposure to niraparib, both preclinical models and phase I trials have shown that tumor concentration ratio is 3 -fold higher of that of the plasma ${ }^{[37,38]}$. It is metabolized in the liver primarily by carboxypeptidases (CEs) in a diphasic process ${ }^{[41,74]}$. The P450 enzymes have a minor role in niraparib metabolism, thus the risk of drug-to-drug interaction is uncommon, as are high aminotransferase levels. Niraparib is metabolized in more than ten non-active metabolites and it is excreted both in its initial formation and its metabolites, in feces $(\sim 39 \%)$ and in urine $(\sim 47 \%)^{[74]}$. Its half life time is 36 hours. No dosage adjustments are needed in mild-tomoderate liver and renal impairment, while there are no pharmacokinetics data and consequently no accurate guidelines for its administration in severe impairments.

Niraparib was initially tested in HRD solid tumors in 2013 and gained approval by both the EMA and the FDA in 2017, based on the results of the ENGOT-OV16/ NOVA trial[75-77]. Among 553 patients with platinumsensitive recurrent OC, 203 were germline BRCA mutation carriers, 138 of whom were assigned to $300 \mathrm{mg}$ niraparib. This group performed significantly better in terms of PFS compared to those on placebo (median 21.0 vs 5.5 months), irrespective of their best achieved response to the last platinum-based therapy. Among the non-germline BRCA mutation cohort, further subgroups were created according to HRD status. Niraparib proved beneficial in almost every subgroup in terms of PFS, chemotherapy-free interval and time to first subsequent treatment. Women with HRD positive tumors experienced significantly prolonged PFS when treated with niraparib compared to placebo (median, 12.9 vs 3.8 months; HR 0.38 ). It is noteworthy that the favorable outcomes of niraparib were retained across subgroups with HRD positive and BRCA-wild type tumors, but also in HRD-negative patients ${ }^{[75-77]}$. In 2019 FDA approved also its use as fourth line treatment in women with HRD ovarian cancer ${ }^{[78]}$.

PRIMA trial consolidated niraparib's pivotal position in patients with HRD ${ }^{[80]}$. HRD status was defined as one of the stratification parameters and 373 women $(50.9 \%)$ with response to first-line chemotherapy were categorized as deficient. In patients with HRD, significant PFS benefit of 21.9 months was reported with niraparib versus 10.4 months compared with placebo (HR:0.43). The risk of progression or death was generally lower in women regardless of HR deficiency or proficiency, but the greater effect was displayed in patients with BRCA-associated tumors ${ }^{[79]}$. The antitumor activity of niraparib has been further illustrated in QUADRA trial, in heavily pretreated platinum-sensitive HRD-positive HGSC patients with no prior exposure to PARPi ${ }^{[80]}$. The following analysis of the primary efficacy group yielded an ORR of $28 \%$ and a median PFS of 5.5 months. The strongest effect with regard to OS was 26 months observed in BRCA-mutant patients, followed by 19 months in the HRD-positive women. Despite the broad range of patient populations in this study, as no restrictions to mutational status or platinum-response were applied, the requirement for PARPi-naive patients and the subsequent per-protocol analysis of results raise concerns regarding the role of PARPi in this line of treatment. Finally, niraparib is about to be tested in the neoadjuvant treatment of ovarian cancer in the phase II NEOPRIMA trial.

\subsection{Talazoparib (BMN 673) (Talzena, Pfizer)}

Talazoparib targets PARP1, $-2,-3$ and tankyrases 1 and 2 . It is unclear where talazoparib owes its unique properties regarding trapping. The theory of the allosteric effects in PARP proteins is questionable, whereas crystalized chiral-center structure could play a role ${ }^{[40,46,81]}$. The phenomenon is even more obvious in populations with $B R C A 1 / 2$ and PTEN dysfunctions. Although potency seems to be associated with bone marrow toxicity in both in vitro and in vivo data, it remains unclear if it is indicative of a better therapeutic result ${ }^{[47]}$.

Talazoparib is available as an oral capsule and the indicated dose for its clinical use as monotherapy is $1 \mathrm{~g}$ daily. After every dose administration it reaches its maximum plasma concentration in 2 hours while it 
needs 2 to 3 weeks from the starting dose to succeed a steady state situation. Food intake has a moderate effect in talazoparib bioavailability, which in general ranges between $55 \%$ - 65\%. Thus, patients can take the drug regardless of meals. It has a low solubility, which is $\mathrm{pH}$ dependent, and moderate permeability, a fact that restricts the delivery of talazoparib in the central nervous system ${ }^{[82]}$. Most of the drug $(>65 \%)$ is eliminated unchanged through urine, while it is a potent p-glycoprotein inhibitor, so co-administration with similar drugs should be avoided ${ }^{[44]}$. No dose adjustments are recommended for mild or moderate renal or hepatic dysfunction, while there are no data for its safety in more severe impairments.

Talazoparib has been mostly investigated in patients with BRCA1/2 mutations and PTEN mutated models, mainly in breast cancer populations, where it has an official treatment approval. As far as ovarian cancer is concerned, the field of investigation is limited in small pilot and phase I/II trials, which test talazoparib as monotherapy with optimistic results, but are still not adequate to forward its further investigation in phase III trials ${ }^{[44,83]}$. Of special interest was the attempt, that tried to find out if the drug could be active after a prior exposure to other PARP inhibitor, which was nevertheless, early terminated (NCT02326844) $)^{[84]}$

\subsection{Veliparib (ABT-888) (AbbVie)}

Veliparib is the smallest PARPi and weakest, with regard to its trapping efficacy, whereas it is the most selective together with niraparib. It is orally available and the indicated dose is $400 \mathrm{mg}$ twice daily continuously. It is very rapidly absorbed and food only moderately affects the $\mathrm{C}_{\max }$ and $\mathrm{T}_{\max }$ time, so its administration is independent of meals ${ }^{[42]}$. It is a very soluble molecule, categorized as class I in the BCS, having the ability to penetrate the central nervous system. Veliparib's bioavailability is high and reaches at least $73 \%{ }^{[85]}$. The majority of the drug is excreted unchanged in urine, while $20 \%$ is metabolized in the liver, mainly by CYP2DA. In renal or liver dysfunction, and potentially in CYP2DA insufficiency, drug exposure is increased, however it is not well-documented if a dose adjustment under these circumstances is necessary ${ }^{[43,86]}$. The ongoing trial NCT01366144 which combines veliparib with paclitaxel and carboplatin in solid tumors in patients with liver and renal impairment may elucidate this question. As it does not induce or inhibit the major Cytochromes P450 and it does not seem to significantly interact with P-gp, it is considered safe when co-administered with other drugs $^{[43]}$.
Veliparib's efficacy was established in early phase trials, demonstrating promising antitumor activity ${ }^{[87,88]}$. In another phase 2 study, the results of 50 enrolled patients with germline BRCA mutations and recurrent $\mathrm{OC}$ were not as remarkable ${ }^{[89]}$. Responses were reported in $35 \%$ of patients with platinum-sensitive, as compared to $20 \%$ of those with platinum-resistant disease; however, this difference did not reach statistical significance. Veliparib has still not managed to gain an approval in the treatment of ovarian cancer in any setting of disease, neither in USA nor in Europe. Combination treatment with veliparib will be discussed below.

\subsection{Novel PARP inhibitors}

Fluzoparib (SHR-3162) is a new PARP1 inhibitor, orally bioavailable, with favorable pharmacokinetic properties and tolerability in phase I trials. It has shown efficacy in HRD tumors, especially in platinum sensitive ovarian carcinomas ${ }^{[90,91]}$. Currently, ongoing phase III trials investigate the potent efficacy of fluzoparib as maintenance treatment in platinum-sensitive recurrent ovarian cancer (NCT03863860), and furthermore its combination with apatinib (VEGFR2 inhibitor) in the $1^{\text {st }}$ line maintenance setting (NCT04229615).

Pamiparib (BGB-290) is another new PARP 1/2 inhibitor with high selectivity and capability to penetrate the central nervous system ${ }^{[92]}$. As all other PARPis, pamiparib is orally disposable. It is currently under investigation as maintenance treatment in platinumsensitive ovarian cancer (NCT03519230), and in BRCA1/2 mutated ovarian cancer (NCT03933761) (93, 94] $^{\text {. }}$

E7449 (2X-121) is also an oral PARP $1 / 2$ and tankyrases $1 / 2$ inhibitor, which can enter the bloodbrain barrier. Its action seems to be independent of p-glycoprotein expression. As many of the already known PARP inhibitors, it has been tested in preclinical $B R C A 1 / 2$ mutated models alone or with alkylating drugs, proving its antitumor activity and its capacity to potentiate DNA-damaging ${ }^{[95]}$. At the moment, it is being tested within a phase II trial (NCT03878849) as a $3^{\text {rd }}$ line treatment in recurrent ovarian cancer, regardless of BRCA or HR status ${ }^{[96]}$.

\section{PARP inhibitors and treatment combinations}

Overall, treatment with PARPis offers a modest survival benefit and furthermore is characterized by primary and secondary resistance. A selection of PARPi combinations can lead to a promising outcome. It would have been 
Table 2: Completed clinical trials of olaparib combinations with other agents in ovarian cancer.

\begin{tabular}{|c|c|c|c|c|c|c|}
\hline Study & Combination & Year & Phase & Cancer type & Olaparib dosage & Outcome \\
\hline NCT00516438 & Topotecan & 2009 & 1 & Solid tumors & $\begin{array}{l}\text { Starting with cap 50mg } \\
\text { BID }^{\circ} \text { continuously, } \\
\text { escalating }\end{array}$ & Unacceptable toxicity \\
\hline NCT00572364 & Dacarbazine & 2009 & 1 & Solid tumors & $\begin{array}{l}\text { Cap 10mg BID } \\
\text { continuously }\end{array}$ & Tolerated, no clinical benefit \\
\hline NCT00710268 & Bevacizumab & 2015 & I & Solid tumors & Cap 400mg BID & Well tolerated \\
\hline NCT00819221 & Lip-doxorubicin & 2017 & 1 & Ovarian cancer & $\begin{array}{l}\text { Cap 150mg BID, } \\
\text { continuously }\end{array}$ & Tolerated and clinical benefit \\
\hline $\begin{array}{l}\text { NCT02430311, } \\
\text { Chinese } \\
\text { population }\end{array}$ & Paclitaxel & 2019 & I & Solid tumors & Tb 100mb BID & $\begin{array}{l}\text { Reduce of olaparib } \\
\text { bioavailability }\end{array}$ \\
\hline NCT01650376 & $\begin{array}{l}\text { Carboplatin and } \\
\text { weekly paclitaxel }\end{array}$ & 2019 & $\mathrm{lb}$ & Ovarian cancer & $\begin{array}{l}\text { Tb 150mg BID } \\
\text { continuously }\end{array}$ & $\begin{array}{l}\text { Tolerated- clinical benefit in } \\
\text { BRCAm }\end{array}$ \\
\hline $\begin{array}{l}\text { GEIC01601- } \\
\text { ROLANDO trial }\end{array}$ & Lip-doxorubicin & 2019 & $\|$ & $\begin{array}{l}\text { Ovarian cancer, } \\
\text { Platinum-resistant }\end{array}$ & $\begin{array}{l}\text { Tb } 300 m g \text { BID } \\
\text { continuously }\end{array}$ & $\begin{array}{l}\text { Not recruiting, waiting for } \\
\text { results }\end{array}$ \\
\hline NCT01081951 & $\begin{array}{l}\text { Carboplatin and } \\
\text { paclitaxel }\end{array}$ & 2020 & $\|$ & $\begin{array}{l}\text { Ovarian cancer- } \\
\text { relapsed, platinum- } \\
\text { sensitive }\end{array}$ & $\begin{array}{l}\text { Cap 200mg BID } \\
\text { continuously }\end{array}$ & $\begin{array}{l}\text { PFS: } 12.2 \text { months (combo) } \\
\text { vs } 9.6 \text { months (carboplatin/ } \\
\text { paclitaxel), HR : } 0.51 \\
\quad(p=0.0012) \\
\text { OS: data not yet available }\end{array}$ \\
\hline
\end{tabular}

${ }^{\circ} \mathrm{BID}$ : bis in die, twice daily

expected that such combinations would have been tried mostly with chemotherapeutic agents (platinum salts, alkylating agents, topoisomerase inhibitors), as PARP inhibition potentiate their cytotoxic activity. Instead, many different categories of antitumor-drugs in combination with PARPis have been investigated in OC, namely antiangiogenetic agents, immunotherapy (immune checkpoint inhibitors) and DNA damage repair targets. Furthermore, they can be combined as a component of a triplet, such as the addition of immunotherapy and bevacizumab to PARP inhibitor therapies ${ }^{[97]}$.

\subsection{Combination with chemotherapy}

Several trials have been conducted combining PARPis with chemotherapy in different types of cancer. Table 2 shows olaparib's combinations with chemotherapy agents. Regarding Olaparib's combination treatment with the classic chemotherapeutic drugs, namely carboplatin and paclitaxel in the platinum-sensitive setting and liposomic doxorubicin in the platinumresistant setting, have been attempted. Both treatment strategies had promising clinical responses in terms of ORR and PFS benefit, especially for the subgroup of BRCA mutant patients ${ }^{[98-101]}$. In spite of this, no phase III trials have been conducted to investigate if this is an effective treatment strategy, maybe due to overlapping myelosuppression, modifying treatment strategies to metronomic schedules. Moreover, paclitaxel and carboplatin combination with olaparib are now investigated in the neoadjuvant treatment of BRCA mutant ovarian cancer (germline and/or somatic) in the active, phase II NUVOLA trial.

Rucaparib is now under investigation as a combination treatment with many other therapeutic agents. Table 3 demonstrates all the currently ongoing rucaparib's combination trials. Combination treatment of rucaparib with chemotherapy has been reported only within phase 1 trials, and proved to be safe ${ }^{[65]}$. According to our knowledge, there are no clinical trials which combine niraparib with alkylating agents. Talazoparib, is another PARPi which has been combined with other agents in early phase trials, especially with alkylating drugs (carboplatin and temozolamide) and the topoisomerase 1 inhibitor irinotecan, playing the role of the chemosensitizer ${ }^{[82,102,103]}$. Limited data exist regarding its safety and efficacy in combination with chemotherapeutic agents in OC.

Veliparib's unique characteristic to act as a sensitizing factor for radiotherapy and chemotherapy increases its DNA-damaging efficacy ${ }^{[92]}$, making veliparib perhaps the ideal PARP inhibitor for potential combinations. It has been combined with many different chemotherapy agents such as alkylating agents, paclitaxel, liposomic doxorubicin, and topoisomerase inhibitors, proving to be tolerable in phase I trials and sometimes also effective (Table 4) [104${ }^{108]}$. It has been also investigated as a radiosensitizer in peritoneal carcinomatosis, in a small phase I trial which included only 4 patients with ovarian cancer. The combination was tolerable, while only one gBRCA 
Table 3: Recruiting clinical trials of olaparib combinations with other agents in ovarian cancer.

\begin{tabular}{|c|c|c|c|c|}
\hline Study & Combination & Year & Phase & Cancer type \\
\hline NCT03772561 & Durvalumab & 2018 & 1 & Solid tumors \\
\hline NCT03682289 & ATR kinase inhibitor AZD6738 & 2019 & $\|$ & Solid tumors \\
\hline NCT02485990 & Tremelimumab & 2020 & 1 & $\begin{array}{c}\text { Recurrent or persistent } \\
\text { ovarian cancer }\end{array}$ \\
\hline NCT02953457 & $\begin{array}{l}\text { Durvalumab and } \\
\text { tremelimumab }\end{array}$ & 2016 & II & $\begin{array}{c}\text { Recurrent or resistant Mbrca } \\
\text { Ovarian cancer }\end{array}$ \\
\hline NCT04123366 & Pebrolizummab & 2020 & $\|$ & Solid tumors, mHRD, dHRD \\
\hline NCT03162627 & Selumetinib & 2017 & $|/| \mid$ & $\begin{array}{c}\text { Endometrial, Ovarian cancer } \\
\text { and other solid tumors }\end{array}$ \\
\hline $\begin{array}{l}\text { NCT03462342 } \\
\text { (CAPRI Trial) }\end{array}$ & Ceralasertib (AZD6738) & 2018 & $\|$ & Recurrent Ovarian cancer \\
\hline NCT03579316 & Adavosertib & 2018 & $\|$ & Ovarian cancer \\
\hline
\end{tabular}

Table 4: Clinical trials of veliparib combinations with other agents in ovarian cancer.

\begin{tabular}{|c|c|c|c|c|c|c|}
\hline Study & Combination & Year & Phase & $\begin{array}{c}\text { Cancer } \\
\text { type }\end{array}$ & $\begin{array}{c}\text { Rucaparib } \\
\text { dosage }\end{array}$ & $\begin{array}{l}\text { Statuts / } \\
\text { Outcome }\end{array}$ \\
\hline NCT02470585 & Topototecan & 2017 & $1 / I I$ & $\begin{array}{c}\text { Resistant/Partially } \\
\text { Sensitive Ovarian cancer }\end{array}$ & $\begin{array}{l}30 \mathrm{mg} \mathrm{BID} \text {, on D1-3 } \\
\text { and } 8-10 \text {, q28 }\end{array}$ & $\begin{array}{l}\text { Well tolerated, Best } \\
\text { response - SD in 37\% }\end{array}$ \\
\hline NCT01113957 & Temozolamide & 2018 & $\|$ & $\begin{array}{c}\text { Recurrent Ovarian } \\
\text { cancer }\end{array}$ & NA & $\begin{array}{c}\text { Completed No Results } \\
\text { yet }\end{array}$ \\
\hline $\begin{array}{l}\text { NCT02470585 - } \\
\text { VELIA trial }\end{array}$ & Carboplatin and Paclitaxel & 2019 & III & $\begin{array}{l}\text { Newly diagnosed } \\
\text { Ovarian cancer }\end{array}$ & $\begin{array}{l}\text { Induction: } 150 \text { mg } \\
\text { BID q21 } \\
\text { Maintenance: } 300 \\
\text { BID for } 2 \text { weeks, } \\
\text { escalating to } 400 \\
\text { mg BID }\end{array}$ & $\begin{array}{c}\text { PFS } 23.5 \text { vs } 17.3 \\
\text { months }(H R=0.68 ; P \\
<.001)\end{array}$ \\
\hline \multirow{2}{*}{$\begin{array}{l}\text { Japanese trial } \\
\text { NCT01459380 }\end{array}$} & Paclitaxel- carboplatin & 2016 & 1 & $\begin{array}{l}\text { Newly diagnosed } \\
\text { Ovarian cancer }\end{array}$ & $\begin{array}{c}\text { 100mg - 150mg } \\
\text { BID q21 }\end{array}$ & $\begin{array}{l}\text { Well tolerated/ potential } \\
\text { clinical benefit }\end{array}$ \\
\hline & $\begin{array}{l}\text { Pegylated Liposomal } \\
\text { Doxorubicin and } \\
\text { carboplatin +/- } \\
\text { bevacizumab }\end{array}$ & 2015 & 1 & $\begin{array}{l}\text { Recurrent, platinum- } \\
\text { sensitive ovarian cancer }\end{array}$ & $\begin{array}{l}50 \mathrm{mg} \text { or } 80 \mathrm{mg} \text { Or } \\
120 \mathrm{mg}\end{array}$ & $\begin{array}{l}\text { Well tolerated in low } \\
\text { doses of veliparib }\end{array}$ \\
\hline NCT01233505 & $\begin{array}{l}\text { Capecitabine and } \\
\text { oxaliplatin }\end{array}$ & 2014 & 1 & Solid tumors & $\begin{array}{l}\text { 40mg BID days 1-7, } \\
\text { 15-21, q28 }\end{array}$ & Well tolerated \\
\hline NCT01306032 & Cyclophosphamide & 2016 & $\|$ & $\begin{array}{l}\text { Refractory BRCA- } \\
\text { Positive Ovarian Cancer } \\
\text { and Breast cancer }\end{array}$ & 60mg daily & $\begin{array}{l}\text { Well tolerated/ no PFS } \\
\text { benefit }\end{array}$ \\
\hline NCT00989651 & $\begin{array}{c}\text { Bevacizumab and } \\
\text { Paclitaxel plus either } \\
\text { carboplatin or IP cisplatin }\end{array}$ & 2009 & 1 & Ovarian cancer & $\mathrm{N} / \mathrm{A}$ & Active-not recruiting \\
\hline
\end{tabular}

${ }^{\circ} \mathrm{BID}$ : bis in die, twice daily

mutated patient with platinum sensitive disease achieved a response ${ }^{[109]}$. Recently, results of VELIA trial, which tested the addition of veliparib to the standard neoadjuvant therapy and its continuation as maintenance therapy, were announced ${ }^{[90]}$. Of the 1140 patients randomized, 214 had a germline $B R C A$ mutation, while 84 had a BRCA mutation of somatic origin. Three nested cohorts of BRCA mutation, HRD and intention-to-treat population were prespecified. In general, substantial PFS benefit was demonstrated across all cohorts for the veliparib-throughout group.
In the intention-to-treat cohort, median PFS was 23.5 versus 17.3 months for the veliparib-throughout and control group respectively (HR 0.68). Similarly, in the BRCA mutant population, a median PFS of 34.7 months was achieved in the veliparib-throughout group compared to 22.0 months in the control group (HR 0.44). The HRD cohort population achieved significantly longer PFS in comparison with the control group (median, 31.9 vs 20.5 months; HR 0.57). Women with $B R C A$ mutations appeared to derive the greatest advantage from PARPi therapy, while those with HRD 
carcinomas had a borderline significant reduction in risk of progression or death. Interestingly, these differences were not observed during comparisons of the veliparib-combination-only with the control group, in either cohort ${ }^{[91]}$. Therefore, the role of veliparib as an addition to induction chemotherapy, remains questionable.

\subsection{Combination with antiangiogenic agents}

The inhibition of PARP enzymes in parallel with the VEGF pathways seems also an effective strategy. The addition of cediranib, an anti-VEGFR inhibitor, to olaparib vs. olaparib alone demonstrated clinical activity not only in women with recurrent, platinum-sensitive OC, but also in platinum resistant disease ${ }^{[110-112]}$. Surprisingly, subgroup analysis revealed that patients without germline BRCA mutations performed better with the combination, compared to BRCA mutant patients, in terms of both PFS and $\mathrm{RR}^{[111]}$. Updated analysis revealed no OS benefit for the combination in the overall population, though OS was significantly increased by the cediranib/olaparib combination in the BRCA wildtype patients ${ }^{[13]}$. The same combination when tested in the phase III GY004 trial, failed to meet its primary PFS endpoint in platinum-sensitive relapsed ovarian cancer, compared to standard of care chemotherapy[114].

While most olaparib trials referred to patients with germline BRCA-associated OC, PAOLA-1 trial was designed to assess olaparib and bevacizumab as firstline maintenance treatment combination in high-grade OC patients, irrespective of BRCA status ${ }^{[115]}$. Women were randomized to receive maintenance bevacizumab with either olaparib or placebo for a maximum of two years. The intention was to determine whether there would be synergistic benefit in combining bevacizumab with olaparib. In the intention-to-treat population there was a 6-month improvement in PFS with the combination (HR: 0.59). Impressively, in the HRDpositive patient population the HR was 0.33 . However, the trial has been criticized for not including an olaparib monotherapy arm, meaning adding a third arm that would have been placebo plus olaparib, so that we can really define the relative contribution of the addition of bevacizumab to olaparib in the BRCA-mutated and HRD population.

Many ongoing trials investigate tolerability and efficacy of different niraparib combinations with other agents (Table 5). Thus far, niraparib has been examined as definitive treatment with bevacizumab, compared to niraparib alone, in women with platinum- sensitive, relapsed HGSOC in AVANOVA2 phase 2 study ${ }^{[116]}$. Stratification was based on HRD status and chemotherapy-free interval following previous therapy. In general, PFS was significantly prolonged for the combination group, regardless of HRD status (median, 11.9 months vs 5.5 ; HR 0.35 ) and origin of $B R C A$ mutation (germline or somatic).

\subsection{Combination with immunotherapy}

Based on preclinical studies that suggested PARP inhibition may create a more immunogenic tumor milieu in OC, combination of PARPis with immune checkpoint inhibitors proceeded to early phase clinical trials. Olaparib and durvalumab, initially tested in germline-mutated (gBRCAm) platinum-sensitive OC, showed modest clinical activity in recurrent $\mathrm{OC}^{[117,118]}$. Combination of pembrolizumab with niraparib has been tested in women with relapsed, platinum-resistant, BRCA-mutant and HRD OC, in the phase 1/2 TOPACIO/ KEYNOTE-162 trial[119]. ORR was estimated at $18 \%$ for somatic BRCA-mutant and 14\% for the HRD-positive women, respectively. Although antitumor effect was reported in all subgroups regardless of their biomarker status, intriguingly, long-term responses appeared to especially favor women with platinum-refractory or resistant disease and $B R C A$ wild type or HRD-negative tumors. Another combination trial which did not meet its primary endpoint of improving PFS in patients with OC and has since been discontinued, is JAVELIN Ovarian PARP 100 trial, in which talazoparib was tested together with avelumab, an anti-PDL1 agent ${ }^{[120]}$. The decision upon discontinuation, also made due to the modest benefit observed with avelumab in frontline OC in JAVELIN Ovarian 100. Translational research studies indicate that VEGFNEGFR pathway blockade would be necessary for improved efficacy of this combination. As a consequence, triplet combinations are already being tested in early phase clinical trials.

\subsection{Combination with other targeted agents}

Future is focused on combinations with the before mentioned effective therapies in phase II and III trials, trying to overcome resistance and improve patient outcomes. At the same time, into play come new target agents, such as the MEK and PI3K inhibitors, most of the times in the recurrence phase of ovarian cancer. Selumetinib, a novel MEKi, having shown antitumor activity in recurrent low grade serous ovarian cancer 
Table 5: Clinical trials of niraparib combinations with other agents in ovarian cancer.

\begin{tabular}{|c|c|c|c|c|c|c|}
\hline Study & Combination & Year & Phase & Cancer type & $\begin{array}{l}\text { Niraparib } \\
\text { dosage }\end{array}$ & Statuts / Outcome \\
\hline NCT04217798 & Etoposide & 2020 & $\|$ & $\begin{array}{l}\text { Resistant/Refractory } \\
\text { Ovarian cancer }\end{array}$ & 200mg daily & To be initiated \\
\hline NCT04149145 & $\begin{array}{l}\text { M4344 - ATR } \\
\text { inhibitor }\end{array}$ & 2020 & $|/| \mid$ & $\begin{array}{l}\text { Resistant/Recurrent } \\
\text { Ovarian cancer }\end{array}$ & $\begin{array}{l}\text { Starting with } \\
\text { 100mg, escalating } \\
\text { to } 200 \mathrm{mg}\end{array}$ & To be initiated \\
\hline NCT03895788 & Brivanib & 2019 & 1 & $\begin{array}{l}\text { Recurrent Ovarian } \\
\text { cancer }\end{array}$ & $\begin{array}{c}100 \mathrm{mg} \text { or } 200 \mathrm{mg} \\
\text { daily }\end{array}$ & Recruiting \\
\hline $\begin{array}{l}\text { NCT03602859- } \\
\text { ENGOT-OV44 /FIRST } \\
\text { study }\end{array}$ & $\begin{array}{l}\text { Dostarlimab - anti- } \\
\text { PD-1 }\end{array}$ & 2018 & III & $\begin{array}{l}1^{\text {st }} \text { line non-mucinous } \\
\text { Ovarian cancer }\end{array}$ & 300mg daily & Recruiting \\
\hline NCT03695380 & $\begin{array}{l}\text { Cobimetinib +/- } \\
\text { Atezolizumab }\end{array}$ & 2018 & $\mathrm{lb}$ & $\begin{array}{l}\text { Platinum sensitive } \\
\text { ovarian cancer }\end{array}$ & 200mg daily & Recruiting \\
\hline $\begin{array}{l}\text { NCT03955471 - } \\
\text { MOONSTONE trial }\end{array}$ & $\begin{array}{l}\text { TSR-042 } \\
\text { anti-PD-1 }\end{array}$ & 2019 & $\|$ & $\begin{array}{l}\text { Recurrent platinum- } \\
\text { resistant Ovarian } \\
\text { cancer }\end{array}$ & N/A & Recruiting \\
\hline $\begin{array}{l}\text { ENGOT-OV24- } \\
\text { NSGO/AVANOVA } \\
\text { trial }\end{array}$ & Bevacizumab & 2019 & $|/| \mid$ & $\begin{array}{l}\text { Ovarian cancer, } \\
\text { Platinum-sensitive }\end{array}$ & 300mg D1-21 & $\begin{array}{c}\text { PFS benefit with the } \\
\text { combination }[11,9 \text { months } \\
(95 \% \mathrm{Cl} 8,5-16,7) \text { vs } 5,5 \\
\text { months }(3,8-6,3)], \text { HR } 0,35 \\
(95 \% \mathrm{Cl} 0 \cdot 21-0 \cdot 57), \mathrm{p}<000,1+\end{array}$ \\
\hline NCT04267939 & $\begin{array}{l}\text { BAY1895344 } \\
\text { ATR inhibitor }\end{array}$ & 2020 & $\mathrm{lb}$ & $\begin{array}{l}\text { PARPi naïve and with } \\
\text { a platinum-resistant/ } \\
\text { refractory disease } \\
\text { or PD after PARPi } \\
\text { maintenance }\end{array}$ & $\mathrm{N} / \mathrm{A}$ & Recruiting \\
\hline $\begin{array}{l}\text { NCT03574779 OPAL } \\
\text { trial }\end{array}$ & $\begin{array}{l}\text { Dostarlimab and } \\
\text { bevacizumab }\end{array}$ & 2018 & $\|$ & $\begin{array}{l}\text { Recurrent Ovarian } \\
\text { cancer }\end{array}$ & $\begin{array}{l}200 \mathrm{mg} \text { or } 300 \mathrm{mg} \\
\text { daily }\end{array}$ & $\begin{array}{c}\text { Active - not recruiting- no } \\
\text { results yet }\end{array}$ \\
\hline $\begin{array}{l}\text { NCT03326193 - } \\
\text { OVARIO trial }\end{array}$ & bevacizumab & 2018 & $\|$ & $\begin{array}{l}\text { Platinum sensitive } \\
\text { Ovarian cancer }\end{array}$ & $300 \mathrm{mg}$ daily & $\begin{array}{c}\text { Active - not recruiting- no } \\
\text { results yet }\end{array}$ \\
\hline $\begin{array}{l}\text { NCT03598270 - } \\
\text { ANITA trial }\end{array}$ & Atezolizumab & 2018 & III & $\begin{array}{l}\text { Platinum sensitive } \\
\text { relapse }\end{array}$ & $\begin{array}{l}200 \mathrm{mg} \text { or } 300 \mathrm{mg} \\
\text { daily }\end{array}$ & Recruiting \\
\hline $\begin{array}{l}\text { NCT02657889 } \\
\text { - TOPACIO/ } \\
\text { KEYNOTE-162 trial }\end{array}$ & Pebrolizumab & & $|/| \mid$ & $\begin{array}{l}\text { Triple negative Breast } \\
\text { cancer or recurrent } \\
\text { ovarian cancer }\end{array}$ & $200 \mathrm{mg}$ & $\begin{array}{l}\text { ORR of } 25 \% \text { in all PROC and } \\
\text { ORR of } 45 \% \text { in tBRCAmut } \\
\text { patients, well tolerated }\end{array}$ \\
\hline NCT03154281 & Everolimus & 2017 & 1 & $\begin{array}{l}\text { Recurrent ovarian or } \\
\text { breast cancer }\end{array}$ & $\begin{array}{l}100 \mathrm{mg} \text { or200mg } \\
\text { or } 300 \mathrm{mg} \text { daily }\end{array}$ & Recruiting \\
\hline NCT03586661 & Copanlisib & 2018 & 1 & $\begin{array}{l}\text { Endometrial and } \\
\text { Ovarian cancer }\end{array}$ & Escalating dose & Recruiting \\
\hline
\end{tabular}

+ Mirza MR, Lundqvist EA, Birrer MJ, Christensen RP, Nyvang GB, Malander S, et al. Niraparib Plus Bevacizumab Versus Niraparib Alone for PlatinumSensitive Recurrent Ovarian Cancer (NSGO-AVANOVA2/ENGOT-ov24): A Randomised, Phase 2, Superiority Trial. Lancet Oncol 2019;20(10): 1409-19. * Konstantinopoulos PA, Waggoner S, Vidal GA, Mita M, Moroney JW, Holloway R, et al. Single-Arm Phases 1 and 2 Trial of Niraparib in Combination With Pembrolizumab in Patients With Recurrent Platinum-Resistant Ovarian Carcinoma. JAMA oncol 2019;5(8):1141-9.

and ER positive HGSOC ${ }^{[121,122]}$, it is now tested in early phase clinical trials in combination with olaparib (NCT03162627). On the other hand, preliminary clinical evidence of synergism between olaparib and alpelisib has paved the way to further investigation ${ }^{[123]}$. Furthermore, targeting more than one DNA repair pathway, including ATR, ATM, Chk1, Wee1 and DNA$P K$, has the potential to enhance responses to PARP inhibitors. Other agents having shown activity in combination with PARPis, particularly in preclinical studies and early phase trials, are HDAC inhibitors and hypomethylating agents ${ }^{[124,125]}$. Table 6 shows olaparib's combination trials with immunotherapy, HDAC inhibitors and hypomethylating agents.

\section{Mechanisms of PARP inhibitor resistance in HR deficient tumor cells}

The BRCA1/2 proteins function in two characteristic cellular processes, the execution of HR repair and the protection of the stalled replication fork. Tumor cells can become resistant to PARPi by two general mechanisms. The first is that the tumor cells can find a way to restore HR repair, most likely by producing a somatic reversion of the mutated BRCA1/2 allele ${ }^{[126]}$. A second mechanism involves that the tumor cell develops a bypassing process for protecting its replication fork. In this second case, the PARPi resistant tumor may still have an HR defect, but will not respond to PARPi exposure ${ }^{[126]}$. In 
Table 6: Clinical trials of rucaparib combinations with other agents in ovarian cancer.

\begin{tabular}{|c|c|c|c|c|c|c|}
\hline Study & Combination & Year & Phase & Cancer type & $\begin{array}{c}\text { Rucaparib } \\
\text { dosage }\end{array}$ & $\begin{array}{l}\text { Statuts / } \\
\text { Outcome }\end{array}$ \\
\hline $\begin{array}{l}\text { NCT03462212 } \\
\text { (MITO25) }\end{array}$ & $\begin{array}{c}\text { Carboplatin/Paclitaxel +/- } \\
\text { Bevacizumab }\end{array}$ & 2018 & $\|$ & $\begin{array}{l}\text { Resistant/Refractory } \\
\text { Ovarian cancer }\end{array}$ & $\begin{array}{l}400 \mathrm{mg} \text { or } \\
500 \mathrm{mg} \text { Or } \\
600 \mathrm{mg} \mathrm{BID}\end{array}$ & Recruiting \\
\hline ATHENA trial & Nivolumab & 2018 & $1 / I I$ & $\begin{array}{c}\text { Platinum Sensitive Ovarian } \\
\text { cancer }\end{array}$ & 600mg BID & Recruiting \\
\hline NCT03840200 & Ipatasertib (Akt inhibitor) & 2019 & $\mathrm{lb}$ & $\begin{array}{c}\text { Breast, Prostate and } \\
\text { Ovarian cancer }\end{array}$ & 600mg BID & Recruiting \\
\hline NCT02873962 & Nivolumab and bevacizumab & 2016 & $\|$ & $2^{\text {nd }}$ line Ovarian cancer & 600mg BID & Recruiting \\
\hline $\begin{array}{l}\text { NCT03992131 } \\
\text { (SEASTAR trial) }\end{array}$ & $\begin{array}{c}\text { Lucitanib (VEGF 1-3 inhibitor) } \\
\text { or Sacituzumab (anti-Trop-2 } \\
\text { monoclonal antibody linked } \\
\text { with SN-38) }\end{array}$ & 2019 & I/ II & Solid tumors & $600 \mathrm{mg}$ BID & Recruiting \\
\hline $\begin{array}{l}\text { NCT03824704 - } \\
\text { ARIES trial }\end{array}$ & Nivolumab & 2019 & $\|$ & $\begin{array}{c}\text { Platinum sensitive recurrent } \\
\text { Ovarian cancer }\end{array}$ & $\mathrm{N} / \mathrm{A}$ & $\begin{array}{l}\text { Active/ not } \\
\text { Recruiting }\end{array}$ \\
\hline NCT03552471 & $\begin{array}{l}\text { Mirvetuximab Soravtansine } \\
\text { (olate receptor alpha targeting } \\
\text { antibody-drug conjugate ) }\end{array}$ & 2018 & I & Recurrent Ovarian cancer & 600mg BID & Recruiting \\
\hline NCT04267939 & $\begin{array}{l}\text { BAY1895344 } \\
\text { ATR inhibitor }\end{array}$ & 2020 & $\mathrm{lb}$ & $\begin{array}{c}\text { PARPi naïve and with a } \\
\text { platinum-resistant/refractory } \\
\text { disease or PD after PARPi } \\
\text { maintenance }\end{array}$ & $\mathrm{N} / \mathrm{A}$ & Recruiting \\
\hline $\begin{array}{l}\text { NCT03574779 } \\
\text { OPAL trial }\end{array}$ & Dostarlimab and bevacizumab & 2018 & $\|$ & Recurrent Ovarian cancer & $\begin{array}{l}\text { 200mg or } \\
300 m g \text { daily }\end{array}$ & $\begin{array}{l}\text { Active }- \text { not } \\
\text { recruiting- no results } \\
\text { yet }\end{array}$ \\
\hline $\begin{array}{l}\text { NCT03326193 - } \\
\text { OVARIO trial }\end{array}$ & bevacizumab & 2018 & $\|$ & $\begin{array}{c}\text { Platinum sensitive Ovarian } \\
\text { cancer }\end{array}$ & 300mg daily & $\begin{array}{l}\text { Active - not } \\
\text { recruiting- no results } \\
\text { yet }\end{array}$ \\
\hline
\end{tabular}

'BID: bis in die, twice daily

this setting, there is often an upregulation of the ATR/ CHK1 pathway, thereby activating the phosphorylation of multiple proteins contributing to fork stability ${ }^{[126]}$.

\subsection{Hypomorphic BRCA1 or BRCA2 allele}

Analysis of $B R C A 1$ missense mutations suggests that the conserved $\mathrm{N}$ - and $\mathrm{C}$-terminal domains are most important for the response to HR-deficiency targeted therapies. Specifically, tumors carrying the BRCA1C61G mutation which disrupts the N-terminal RING domain respond poorly to PARPis, and rapidly develop resistance $^{[127]}$. Interestingly, mutations in the BRCACterminal (BRCT) domain of BRCA1 commonly create protein products that are subject to protease-mediated the BRCT domain of these mutant BRCA1 proteins under PARP inhibitor selection pressure ${ }^{[128]}$. The HSP90-stabilized mutant BRCA1 proteins can efficiently interact with PALB2-BRCA2-RAD51, form RAD51 foci, and confer PARP inhibitor and cisplatin resistance. Treatment of resistant cells with an HSP90 inhibitor may reduce the mutant BRCA1 protein level and restore their sensitivity to PARP inhibition ${ }^{[128]}$.

\subsection{Somatic reversion or restoration of open reading frame (ORF)}

In BRCA1/2-mutated tumors, the most common acquired mechanism of resistance to PARPis is secondary intragenic mutations restoring the BRCA1 or BRCA2 protein functionality ${ }^{[129,130]}$. Restoration of BRCA1/2 function occurs either by genetic events that cancel the frameshift caused by the original mutation and restore ORF leading to expression of a functional nearly full length protein which can be similar to the full length wild-type protein. These genetic events were originally observed in BRCA1- and BRCA2-mutated cancer cells under in vitro selective pressure, due to exposure to cisplatin or PARPis and as a result would eventually cause platinum and PARPi resistance ${ }^{[126]}$. This mechanism of resistance is highly clinically relevant for patients with BRCA-mutated cancers who are treated with platinum-based therapy; $46 \%$ of platinum resistant BRCA-mutated HGSOC exhibit tumor-specific secondary mutations that restore the ORF of either BRCA1 or BRCA2 $2^{[126]}$. Lastly, multiple somaticallyreverted BRCA1/2 alleles have been detected from patients undergoing PARPi or platinum therapy through analysis of circulating free DNA (cfDNA) ${ }^{[131]}$. 


\subsection{Epigenetic reversion of BRCA1 promoter hypermethylation}

HR repair can be restored by reversal of $B R C A 1$ promoter methylation. The primary sensitive sample may show extensive promoter methylation and low BRCA1 expression, while the sample from the relapsed disease has lost BRCA1 methylation and the BRCA1 gene is expressed at comparable levels to homologous recombination proficient tumors ${ }^{[126]}$. The loss of BRCA1 promoter methylation may result from an active demethylation event but more likely from a heterogeneous tumor from which the tumor cells with less promoter methylation undergo positive selection in PARPi[126].

\subsection{Loss of PARP expression}

Since PARPis function by blocking the enzymatic action of PARP enzymes, another possible mechanism of PARPi resistance may be decreased expression of PARP enzymes. This mechanism of resistance maybe particularly relevant to the PARP-trapping mechanism of action of PARPis. Interestingly, a recent study identified a PARP1 mutation $(1771 \mathrm{C}>\mathrm{T})$ in an ovarian cancer patient who demonstrated de novo resistance to PARP inhibitor ${ }^{[132]}$.

\subsection{Loss of end resection regulation 53BP1 or REV7}

Several mechanisms of resistance involving reacquisition of DNA end resection capacities have also been described. There are several proteins which are known to working a pathway which suppresses end resection and thereby inhibits $\mathrm{HR}$ repair. These proteins include 53BP1, REV7, PTIP, and RIF1. Discovery of this mechanism came from the observation that the requirement of $B R C A 1$ for $\mathrm{HR}$ can be alleviated by concomitant loss of 53BP1. 53BP1 blocks CtIP-mediated DNA end resection via downstream effectors like Rif1 and PTIP and thus commits DNA repair to CNHEJ ${ }^{[134]}$. Loss of 53BP1 partially restores the HR defect and their hypersensitivity to DNA-damaging agents in knockout mice for BRCA-1 ${ }^{[134]}$.

In BRCA1-mutant cells, loss of 53BP1 confers resistance to PARPi. More recently, a set of new proteins which bind to REV7, including RINN1, -2 , -3 have been

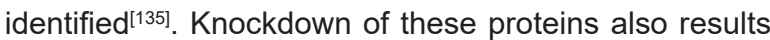
in PARP inhibitor resistance.

\subsection{Resistance due to limited drug uptake or increased drug export}

Pharmacological effects that alter the cellular response to PARPis may also be relevant. Several studies have shown that PARPi responses maybe modified by ATP. binding cassette $(A B C)$ transporters ${ }^{[136]}$. Increased expression in tumor cells of $A B C$ transporters, such as the P-glycoprotein (PgP) efflux pump (also known as multidrug resistance protein 1) have been implicated in reducing the efficacy of many compounds by enhancing their extracellular translocation.

Importantly, BRCA1/2 deficient tumor cells can acquire resistance to PARPi by finding independent mechanisms for protecting their replication forks. Research has demonstrated how the study of drug resistance can uncover novel principles of DNA repair and replication fork biochemistry. Multiple studies have previously demonstrated the role of BRCA1, BRCA2, and other FA proteins in the protection of $\mathrm{RFs}^{[137,138]}$ It has been demonstrated that different nucleases are necessary for fork protection. The first study showed that BRCA1 cells were shown to become resistant to PARPi by reducing the recruitment of the nuclease, MRE11 (required for the RF stability), to the stalled fork, thereby resulting in fork protection through reduced expression of the protein, PTIP ${ }^{[139]}$. In a second study it was demonstrated that BRCA2 deficient tumors cells can become resistant to PARPi by reducing the recruitment of a different nuclease, MUS81, to the stalled fork ${ }^{[140]}$. As a mechanism of PARPi resistance, these tumors downregulate $\mathrm{EZH} 2$ activity at the fork and downregulate MUS81 recruitment ${ }^{[140]}$. Interestingly, through both of these mechanisms, the tumors achieve PARPi resistance without restoring HR repair.

\subsection{PARP Inhibition Induced Akt Activation resistance}

Recently it has been suggested from in vitro trials that inhibition of nuclear protein PolyADP-ribosylation reaction catalyzed by PARP1 somehow triggers the activation of cytoplasmically localized Akt. PARP1 activated by DNA strand breaks PolyADP-ribosylation itself, thereby creating a scaffold that recruits a complex of proteins ${ }^{[141]}$. If excess PARP activation is prevented by a pharmacological inhibitor or genetic manipulation, one of the complex proteins does not undergo ribosylation it translocates to the cytoplasm and in part associates with the mitochondrial outer membrane ${ }^{[142]}$. There, the complex recruits Akt and mTOR, and together with them forms a signalosome that activates Akt, leading to 
activation of downstream pro-survival pathways ${ }^{[143]}$.

\section{PARP inhibitors and adverse events}

PARPis are associated with a variety of adverse events, the type and the severity of which may lead to dose adjustments and modifications or even to the discontinuation of therapy. PARP inhibition is not selective. By interfering with the DNA repair ability of cancer and normal cells, treatment with PARPis can lead to both target specific and non-target specific side effects. Blood toxicity is one of the most common non target specific adverse effects related to PARP inhibition treatment.

Adverse events (AEs) related to PARP inhibition may be class related or drug specific. Class related are the AEs that are observed among all the drugs of the PARP family, while those which are unique to each drug are called drug specific. A meta-analysis examining the differences in class related toxicity between olaparib, niraparib and rucaparib showed that olaparib was related mainly to diarrhea, niraparib to blood toxicity and rucaparib to abdominal pain ${ }^{[144]}$. Close monitoring of patients is necessary, as AEs may affect their health and safety.

\subsection{General and Nutrition Disorders}

Fatigue is the most common AE, presented in $50 \%$ to $70 \%$ of patients receiving PARPis. It is mainly grade 1-2 and most common with rucaparib, niraparib and olaparib ${ }^{[145]}$. According to Coleman et al, the incidence of fatigue with veliparib is about $26 \%$ (88). When not related to hematological toxicity as anemia or thrombocytopenia, activity and physical exercise may be helpful to manage this adverse event. Another class related $A E$ is anorexia and decrease in appetite. This appears to be a common side effect observed in about $20-25 \%$ of patients, to whom nutritional consultation may be necessary ${ }^{[145]}$.

\subsection{Gastrointestinal Toxicity}

A recent meta-analysis has shown that the risk of high grade gastrointestinal toxicities associated with PARPis is significantly increased in ovarian cancer patients, with the exception of constipation ${ }^{[146]}$. Of these, nausea and vomiting seem to appear early on treatment with a tendency to decline later on. According to the SOLO-2 trial, the incidence of all - grade nausea with olaparib was $76 \%$ and of vomiting $37 \%$. Lower incidence rates were reported with diarrhea and stomatitis, 33\% and $20 \%$ respectively (50). Nausea and vomiting related to PARP inhibition usually subside with medication and treatment often involves drugs as metoclopramide, benzodiazepines or 5-HT3 receptor antagonists. Last but not least, dyspepsia (10-20\%) and dysgeusia (10$40 \%$ ) have frequently occurred in patients treated with PARP inhibitor maintenance, the later more commonly noted with rucaparib. Prescription of PPI's and certain dietary and oral hygiene measures may be helpful to control these $\mathrm{AEs}^{[145]}$.

\subsection{Hematologic Toxicity}

Hematologic AEs are very common during treatment with $\mathrm{PARP}$ is and require complete blood counts regularly to exclude enhancing blood toxicity. According to a metaanalysis from Zhou et al including 2479 patients from 12 randomized controlled trials treated with PARPis, the incidence of severe neutropenia, thrombocytopenia and anemia were $32.9 \%, 15.9 \%$ and $9.1 \%$ respectively ${ }^{[147]}$. Hematologic toxicity is more common with niraparib and talazoparib and less with rucaparib, olaparib and veliparib $^{[144]}$. According to one trial, the incidence of neutropenia of any grade in patients on treatment with PARPis is about $20 \%{ }^{[145]}$. On the other hand, febrile neutropenia is extremely rare when the PARP inhibitor is used a single agent ${ }^{[60,73,79]}$. In general, the use of granulocyte growth factors during treatment with PARP inhibitors is not recommended. MDS/AML has been reported as an AE related to PARPi therapy although in a very small percent (approximately 1\%). Exposure to DNA-damaging agents is demonstrated to be a significant risk factor for developing MDS/AML especially in the presence of $B R C A$ mutations ${ }^{[78]}$.

Anemia with hemoglobin levels $<8 \mathrm{~g} / \mathrm{dL}$ generally require interruption of treatment until hemoglobin recovers to $9 \mathrm{~g} / \mathrm{dL}$. Blood transfusions are often required and dose modifications with lower doses are necessary after persistent occurrence of anemia with treatment. PARPis should be withheld when platelet counts are $<100 \times 10^{9}$ cells/L. Treatment adjustment is required when platelet count reduces $<75 \times 10^{9}$ cells $/ L$ or at a second occurrence with the exception of talazoparib, where treatment may be continued if platelet counts are $>50 \times 10^{9}$ cells/L. Severe thrombocytopenia with platelet counts $<10 \times 109$ cells/L require emergency platelet transfusions ${ }^{[145]}$. 


\subsection{Respiratory Disorders}

The most common respiratory symptoms noted on treatment with PARP inhibitors are dyspnea, cough and nasopharyngitis. Usually mild, they affect $10-20 \%$ of patients and may relate to infectious conditions. Clinical and radiographic assessment may be necessary to exclude olaparib related pneumonitis which is reported in $<1 \%{ }^{[145]}$

\subsection{Nervous System Disorders}

Insomnia and headache are frequently related with PARP inhibition. Headache is common with both olaparib and niraparib at a rate of $26 \%$ while insomnia is observed in $27 \%$ of patients who are treated with niraparib. Dizziness is related to niraparib too with an incidence rate of $18 \%$. Pharmacological measures may appear necessary to control refractory cases of drug related neurological adverse events ${ }^{[145]}$.

\subsection{Laboratory Abnormalities}

Transient transaminase elevations have been described mainly with rucaparib. All grade incidences have been reported to be approximately $34 \%$ and usually transaminase normalization occurs after a few weeks from initiation of treatment. Olaparib and niraparib can cause transaminase elevations too, but to a lesser extent than rucaparib ${ }^{[145]}$. Elevations in creatinine have been described in approximately $10-12 \%$ of patients across different PARPis ${ }^{[145]}$. A retrospective trial by Zibetti et al. showed that elevation of blood creatinine levels in patients receiving PARPis was not related to a decrease in the GFR measured by renal scan ${ }^{[148]}$. In the event of persistent blood creatinine rise, other causes should be ruled out before withholding treatment.

\subsection{Cardiac Disorders}

Among cardiac adverse events, hypertension and palpitations occurrence have been related mainly to niraparib. In the NOVA trial, all grade hypertension was noted in $20 \%$ of patients, while palpitations in $10 \%$ respectively (77). This potential may be due to the drug's off-target pharmacologic activity on the dopamine, the norepinephrine and the serotonin transporters ${ }^{[149]}$. Accordingly, thorough investigation is needed to exclude other causes of tachycardia and palpitations, and medication to be used when necessary.

\subsection{Skin Disorders}

Skin disorders related to treatment with PARP inhibitors include rash, pruritus and photosensitivity. In the ARIEL3 clinical trial, $17 \%$ of the patients receiving rucaparib reported photosensitivity, $13 \%$ pruritus and $12 \%$ rash (73). Sun protection and Dermatologic consultation may be indicated.

\section{Conclusions}

Advanced ovarian cancer treatment landscape has changed dramatically since the introduction of PARP inhibitors in clinical practice. Although survival benefit has been shown in clinical trials, treatment resistance remains inevitable. Ongoing clinical trials are testing multiple combinations of PARPis with several agents trying to discover the appropriate combination, as well as, the treatment setting they should be indicated for.

\section{Author Contributions}

Sofia Levva conceived and designed the study. Sofia Levva, Aglaia Skolariki, Eleni Sogka, Alexandros Bokas, Avraam Assi, Marianna Pispirigkou and Panagiotis Koliou provided the study material, collected and assembled the data, analyzed and interpreted the data, and wrote the manuscript. All authors approved the manuscript.

\section{Disclosures}

The authors reported no financial relationships. 
[1] Siegel RL, Miller KD, Jemal A. Cancer statistics, 2020. CA Cancer J Clin 2020;70(1):7-30.

[2] Ferlay J, Colombet M, Soerjomataram I, Dyba T, Randi G, Bettio M, et al. Cancer incidence and mortality patterns in Europe: Estimates for 40 countries and 25 major cancers in 2018. Eur Journal Cancer 2018.

[3] Prat J, FIGO Committee on Gynecologic Oncology. Staging classification for cancer of the ovary, fallopian tube, and peritoneum. Int $\mathrm{J}$ Gynaecol Obstet 2014;124(1):1-5.

[4] Kubalanza K, Konecny GE. Mechanisms of PARP inhibitor resistance in ovarian cancer. Curr Opin Obstet Gynecol 2020;32(1):36-41.

[5] Macheret M, Halazonetis TD. DNA Replication Stress as a Hallmark of Cancer. Annu Rev Pathol 2015;10(1):425-48.

[6] Lengauer C, Kinzler KW, Vogelstein B. Genetic instabilities in human cancers. Nature 1998;396(6712):643-9.

[7] Graziani G, Szabó C. Clinical perspectives of PARP inhibitors. Pharmacol Res 2005;52(1):109_ 18.

[8] Lord CJ, Ashworth A. PARP inhibitors: Synthetic lethality in the clinic. Science 2017;355(6330):1152-8.

[9] Gibson BA, Kraus WL. New insights into the molecular and cellular functions of poly (ADPribose) and PARPs. Nat Rev Mol Cell Biol 2012;13(7):411-24.

[10] Tangutoori S, Baldwin P, Sridhar S. PARP inhibitors: A new era of targeted therapy. Maturitas 2015;81(1):5-9.

[11] Farmer H, McCabe N, Lord CJ, Tutt AN, Johnson DA, Richardson TB, et al. Targeting the DNA repair defect in BRCA mutant cells as a therapeutic strategy. Nature 2005;434(7035):917-21.

[12] Bryant HE, Schultz N, Thomas HD, Parker KM, Flower D, Lopez E, et al. Specific killing of BRCA2deficient tumours with inhibitors of poly(ADPribose) polymerase. Nature 2005;434(7035):9137.

[13] Murai J, Huang SY, Das BB, Renaud A, Zhang Y, Doroshow JH, et al. Trap-ping of PARP1 and PARP2 by clinical PARP inhibitors. Cancer Res 2012;72(21):5588-99.

[14] Ledermann J, Harter P, Gourley C, Friedlander M, Vergote I, Rustin G, et al. Olaparib maintenance therapy in platinum-sensitive relapsed ovarian cancer. New Eng J Med 2012;366(15):1382-92.
[15] Telli ML, Timms KM, Reid J, Hennessy B, Mills $\mathrm{GB}$, Jensen $\mathrm{KC}$, et al: Homologous recombination deficiency (HRD) score predicts response to platinum-containing neoadjuvant chemotherapy in patients with triple-negative breast cancer. Clin Cancer Res 2016;22(15):3764-73.

[16] Maya-Mendoza A, Moudry P, Merchut-Maya JM, Lee M, Strauss R, Bartek J, et al. High speed of fork progression induces DNA replication stress and genomic instability. Nature 2018;559(7713):279-84.

[17] Ubhi T, Brown GW. Exploiting DNA Replication Stress for Cancer Treatment. Cancer Res 2019;79(8):1730-39.

[18] Fong PC, Boss DS, Yap TA, Tutt A, Wu P, MerguiRoelvink $M$, et al. Inhibition of poly(ADP-ribose) polymerase in tumors from BRCA mutation carriers. N Engl J Med 2009;361(2):123-34.

[19] Moschetta M, George A, Kaye SB, Banerjee S. BRCA somatic mutations and epigenetic BRCA modifications in serous ovarian cancer. Ann Oncol 2016;27(8):1449-55.

[20] da Cunha Colombo Bonadio RR, Fogace RN, Miranda VC, Diz MDPE. Homologous recombination deficiency in ovarian cancer: a review of its epidemiology and management. Clinics (Sao Paulo). 2018;73(suppl1):e450s.

[21] Hennessy BTJ, Timms KM, Carey MS, Gutin A, Meyer LA, Flake DD, et al. Somatic mutations in BRCA1 and BRCA2 could expand the number of patients that benefit from poly (ADP ribose) polymerase inhibitors in ovarian cancer. $\mathrm{J}$ Clin Oncol 2010;28(22):3570-6.

[22] Amin N, Chaabouni N, George A. Genetic testing for epithelial ovarian cancer. Best Pract Res Clin Obstet Gynaecol 2020;65:125-38.

[23] Pennington KP, Walsh T, Harrell MI, Lee MK, Pennil CC, Rendi MH, et al. Germline and somatic mutations in homologous recombination genes predict platinum response and survival in ovarian, fallopian tube, and peritoneal carcinomas. Clin Cancer Res 2014;20(3):764-75.

[24] Taniguchi T, Tischkowitz M, Ameziane N, Hodgson SV, Mathew CG, Joenje $H$, et al. Disruption of the Fanconi anemia-BRCA pathway in cisplatin-sensitive ovarian tumors. Nat Med 2003;9(5):568-74.

[25] Cancer Genome Atlas Research Network. Integrated Genomic Analyses of Ovarian Carcinoma The Cancer Genome Atlas Research Network. Nature 2011;474(7353):609-15. 
[26] Lupo B, Trusolino L. Inhibition of poly(ADP-ribosyl) ation in cancer: old and new paradigms revisited. Biochim Biophys Acta 2014;1846(1):201-15.

[27] Yang HJ, Liu VW, Wang Y, Tsang PC, Ngan HY. Differential DNA methylation profiles in gynecological cancers and correlation with clinicopathological data. BMC Cancer 2006;6:212.

[28] Brown LA, Irving J, Parker R, Kim H, Press JZ, Longacre TA, et al. Amplification of EMSY, a novel oncogene on 11q13, in high grade ovarian surface epithelial carcinomas. Gynecol Oncol 2006;100(2):264-70.

[29] Cousineau I, Belmaaza A. EMSY overexpression disrupts the BRCA2/RAD51 pathway in the DNAdamage response: Implications for chromosomal instability/recombination syndromes as checkpoint diseases. Mol Genet Genomics 2011;285(4):325-40.

[30] Hughes-Davies L, Huntsman D, Ruas M, Fuks F, Bye J, Chin SF, et al. EMSY links the BRCA2 pathway to sporadic breast and ovarian cancer. Cell 2003;115(5):523-35.

[31] Norquist BM, Pennington KP, Agnew KJ, Harrell MI, Pennil CC, Lee MK, et al. Characteristics of women with ovarian carcinoma who have BRCA1 and BRCA2 mutations not identified by clinical testing. Gynecol Oncol 2013;128(3):483-7.

[32] Norquist BM, Harrell MI, Brady MF, Walsh T, Lee MK, Gulsuner S, et al. Inherited mutations in women with ovarian carcinoma. JAMA Oncol 2016;2(4):482-90.

[33] Norquist BM, Brady MF, Harrell MI, Walsh T, Lee MK, Gulsuner S, et al. Mutations in homologous recombination genes and outcomes in ovarian carcinoma patients in GOG 218: An NRG oncology/Gynecologic oncology group study. Clin Cancer Res 2018;24(4):777-83.

[34] Constantinou P, Tischkowitz M. Genetics of gynaecological cancers. Best Pract Res Clin Obstet Gynaecol 2017;42:114-24.

[35] Ketabi Z, Bartuma K, Bernstein I, Malander S, Grönberg H, Björck E, et al. Ovarian cancer linked to lynch syndrome typically presents as earlyonset, non-serous epithelial tumors. Gynecol Oncol 2011;121(3):462-5

[36] Kim G, Iso G, McKee AE, Zhang $H$, Tang S, Gwise T, et al. FDA Approval Summary: Olaparib Monotherapy in Patients With Deleterious Germline BRCA-Mutated Advanced Ovarian Cancer Treated With Three or More Lines of Chemotherapy. Clin Cancer Res 2015;21(19):4257-61.
[37] Bundred N, Gardovskis J, Jaskiewicz J, Eglitis J, Paramonov V, McCormack $\mathrm{P}$, et al. Evaluation of the pharmacodynamics and pharmacokinetics of the PARP inhibitor olaparib: a Phase I multicentre trial in patients scheduled for elective breast cancer surgery. Invest New Drugs 2013;31:949_ 58.

[38] Sun K, Mikule K, Wang Z, Poon G, Vaidyanathan A, Smith $G$, et al. A comparative pharmacokinetic study of PARP inhibitors demonstrates favorable properties for niraparib efficacy in preclinical tumor models. Oncotarget 2018;9(98):37080-96.

[39] Liao M, Watkins S, Nash E, Isaacson J, Etter $\mathrm{J}$, Beltman J, et al. Evaluation of absorption, distribution, metabolism, and excretion of [14C]rucaparib, a poly (ADP-ribose) polymerase inhibitor, in patients with advanced solid tumors. Invest New Drugs 2020;38(3):765-75.

[40] Thorsell AG, Ekblad T, Karlberg T, Löw M, Pinto $A F$, Trésaugues $L$, et al. Structural Basis for Potency and Promiscuity in Poly(ADP-ribose) Polymerase (PARP) and Tankyrase Inhibitors. J Med Chem 2017;60(4):1262-71.

[41] van Andel L, Zhang Z, Lu S, Kansra V, Agarwal $S$, Hughes L, et al. Human mass balance study and metabolite profiling of 14C-niraparib, a novel poly(ADP-Ribose) polymerase (PARP)-1 and PARP-2 inhibitor, in patients with advanced cancer. Investig New Drugs 2017;35(6):751-65.

[42] Werner TL, Sachdev J, Swisher EM, Gutierrez M, Kittaneh M, Stein MN, et al. Safety and pharmacokinetics of veliparib extended-release in patients with advanced solid tumors: a phase I study. Cancer Med 2018;7(6):2360-9.

[43] Li J, Kim S, Sha X, Wiegand R, Wu J, LoRusso P. Complex disease-, gene-, and drugdrug interactions: impacts of renal function, CYP2D6 phenotype, and OCT2 activity on veliparib pharmacokinetics. Clin Cancer Res 2014;20:3931-44.

[44] de Bono J, Ramanathan RK, Mina L, Chugh R, Glaspy J, Rafii S, et al. Phase I, dose-escalation, two-part trial of the PARP inhibitor talazoparib in patients with advanced germline BRCA1/2 mutations and selected sporadic cancers. Cancer Discov 2017;7:620-9.

[45] US Food and Drug Administration. Lynparza prescribing information (2017. Update). 2014. https://www.accessdata.fda.gov/drugsatfda docs/label/2017/208558s000lbl.pdf

[46] Hopkins TA, Shi Y, Rodriguez LE, Solomon LR, Donawho CK, DiGiammarino EL, et al. 
Mechanistic dissection of PARP1 trapping and the impact on in vivo tolerability and efficacy of PARP inhibitors. Mol Cancer Res 2015;13:146577.

[47] Hopkins TA, Ainsworth WB, Ellis PA, Donawho CK, DiGiammarino EL, Panchal SC, et al. PARP1 Trapping by PARP Inhibitors Drives Cytotoxicity in Both Cancer Cells and Healthy Bone Marrow. Mol Cancer Res 2019;17(2):409-19.

[48] Plummer $R$, Swaisland $H$, Leunen $K$, van Herpen CM, Jerusalem G, De Grève J, et al. Olaparib tablet formulation: effect of food on the pharmacokinetics after oral dosing in patients with advanced solid tumours. Cancer Chemother Pharmacol 2015;76(4):723-9.

[49] Zhou D, Li J, Bui K, Learoyd M, Berges A, Milenkova T, et al. Bridging Olaparib Capsule and Tablet Formulations Using Population Pharmacokinetic Meta-analysis in Oncology Patients. Clin Pharmacokinet 2019;58(5):615-25.

[50] Pujade-Lauraine E, Ledermann JA, Selle F, Gebski V, Penson RT, Oza AM, et al. Olaparib tablets as maintenance therapy in patients with platinum-sensitive, relapsed ovarian cancer and a BRCA1/2 mutation (SOLO2/ENGOT-Ov21): a double-blind, randomized, placebo-controlled, phase 3 trial. Lancet Oncol 2017;18(9):1274-84.

[51] Audeh MW, Carmichael J, Penson RT, Friedlander M, Powell B, Bell-McGuinn KM, et al. Oral poly(ADP-ribose) polymerase inhibitor olaparib in patients with BRCA1 or BRCA2 mutations and recurrent ovarian cancer: A proof-of-concept trial. Lancet 2010;376(9737):245-51.

[52] Kaye SB, Lubinski J, Matulonis U, Ang JE, Gourley C, Karlan BY, et al. Phase II, openlabel, randomized, multicenter study comparing the efficacy and safety of olaparib, a poly (ADPribose) polymerase inhibitor, and pegylated liposomal doxorubicin in patients with BRCA1 or BRCA2 mutations and recurrent ovarian cancer. J Clin Oncol 2012;30(4):372-9.

[53] Ledermann J, Harter P, Gourley C, Friedlander M, Vergote I, Rustin G, et al. Olaparib maintenance therapy in patients with platinum-sensitive relapsed serous ovarian cancer: a preplanned retrospective analysis of outcomes by BRCA status in a randomised phase 2 trial. Lancet Oncol 2014;15(8):852-61.

[54] Friedlander M, Matulonis U, Gourley C, du Bois A, Vergote I, Rustin G, et al. Long-term efficacy, tolerability and overall survival in patients with platinum-sensitive, recurrent high-grade serous ovarian cancer treated with maintenance olaparib capsules following response to chemotherapy. $\mathrm{Br}$ J Cancer 2018;119(9):1075-85.

[55] Domchek SM, Aghajanian C, Shapira-Frommer R, Schmutzler RK, Audeh MW, Friedlander M, et al. Efficacy and safety of olaparib monotherapy in germline BRCA1/2 mutation carriers with advanced ovarian cancer and three or more lines of prior therapy. Gynecol Oncol 2016;140(2):199_ 203.

[56] Kaufman B, Shapira-Frommer R, Schmutzler RK, Audeh MW, Friedlander M, Balmaña J, et al. Olaparib monotherapy in patients with advanced cancer and a germline BRCA1/2 mutation. J Clin Oncol 2015;33(3):244-50.

[57] Gelmon KA, Tischkowitz M, Mackay H, Swenerton K, Robidoux A, Tonkin K, et al. Olaparib in patients with recurrent high-grade serous or poorly differentiated ovarian carcinoma or triplenegative breast cancer: A phase 2, multicentre, open-label, non-randomised study. Lancet Oncol 2011;12(9):852-61.

[58] Dougherty BA, Lai Z, Hodgson DR, Orr MCM, Hawryluk M, Sun J, et al. Biological and clinical evidence for somatic mutations in BRCA1 and BRCA2 as predictive markers for olaparib response in highgrade serous ovarian cancers in the maintenance setting. Oncotarget 2017;8(27):43653-61.

[59] Ledermann JA, Pujade-Lauraine E. Olaparib as maintenance treatment for patients with platinumsensitive relapsed ovarian cancer. Ther Adv Med Oncol 2019; 11:1758835919849753.

[60] Olaparib makes OS gains in Ovarian Cancer. Cancer Discov 2020;10(7): OF3.

[61] Moore K, Colombo N, Scambia G, Kim BG, Oaknin $A$, Friedlander $M$, et al. Maintenance olaparib in patients with newly diagnosed advanced ovarian cancer. N Engl J Med 2018;379(26):2495-505.

[62] Penson RT, Valencia RV, Cibula D, Colombo N, Leath CA, Bidziński $M$, et al. Olaparib Versus Nonplatinum Chemotherapy in Patients With Platinum-Sensitive Relapsed Ovarian Cancer and a Germline BRCA1/2 Mutation (SOLO3): A Randomized Phase III Trial. J Clin Oncol 2020;38(11):1164-74.

[63] Vanderstichele A, Van Nieuwenhuysen E, Han S, Concin N, Van Gorp T, Berteloot P, et al. Randomized phase II CLIO study on olaparib monotherapy versus chemotherapy in platinum-resistant ovarian cancer. J Clin Oncol 2019;37(15_suppl). Abstract 5507.

[64] Knezevic CE, Wright G, Rix LLR, Kim W, Kuenzi $\mathrm{BM}$, Luo $\mathrm{Y}$, et al. Proteome-wide profiling of 
clinical PARP inhibitors reveals compoundspecific secondary targets. Cell Chem Biol 2016;23(12):1490-1503.

[65] Wilson RH, Evans TJ, Middleton MR, Molife LR, Spicer J, Dieras V, et al. A Phase I Study of Intravenous and Oral Rucaparib in Combination With Chemotherapy in Patients With Advanced Solid Tumours. Br J Cancer 2017:116(7):884-92.

[66] Shapiro GI, Kristeleit RS, Burris HA, LoRusso P, Patel MR, Drew H, et al. Pharmacokinetic Study of Rucaparib in Patients With Advanced Solid Tumors. Clin Pharmacol Drug Dev 2019;8(1):107118.

[67] Parrish K, Cen L, Murray J, Calligaris D, Kizilbash S, Mittapalli RK, et al. Efficacy of PARP Inhibitor Rucaparib in Orthotopic Glioblastoma Xenografts Is Limited by Ineffective Drug Penetration into the Central Nervous System. Mol Cancer Ther 2015;14(12): 2735-43.

[68] Dumus S, Sparidans RW, van Esch A, Wagennar E, Beijnen $\mathrm{JH}$, Schinkel AH. Breast Cancer Resistance Protein (BCRP/ABCG2) and P-glycoprotein (P-GP/ABCB1) Restrict Oral Availability and Brain Accumulation of the PARP Inhibitor Rucaparib (AG-014699). Pharm Res 2015;32:37-46.

[69] Kristeleit RS, Shapiro GI, Burris HA, Oza AM, LoRusso P, Patel MR, et al. A phase I-II study of the oral PARP inhibitor rucaparib in patients with germline BRCA1/2-mutated ovarian carcinoma or other solid tumors. Clin Cancer Res 2017;23(15):4095-106.

[70] Drew Y, Ledermann J, Hall G, Rea D, Glasspool $R$, Highley $M$, et al. Phase 2 multicentre trial investigating intermittent and continuous dosing schedules of the poly(ADP-ribose) polymerase inhibitor rucaparib in germline BRCA mutation carriers with advanced ovarian and breast cancer. Br J Cancer 2016;114(12):e21.

[71] Swisher EM, Lin KK, Oza AM, Scott CL, Giordano $\mathrm{H}$, Sun $\mathrm{J}$, et al. Rucaparib in relapsed, platinumsensitive high-grade ovarian carcinoma (ARIEL2 Part 1): an international, multicentre, open-label, phase 2 trial. Lancet Oncol 2017;18(1):75-87.

[72] Oza AM, Tinker AV, Oaknin A, Shapira-Frommer $\mathrm{R}$, McNeish IA, Swisher EM, et al. Antitumor activity and safety of the PARP inhibitor rucaparib in patients with high-grade ovarian carcinoma and a germline or somatic BRCA1 or BRCA2 mutation: Integrated analysis of data from Study 10 and ARIEL2. Gynecol Oncol 2017;147(2):267-75.

[73] Coleman RL, Oza AM, Lorusso D, Aghajanian C, Oaknin A, Dean A, et al. Rucaparib maintenance treatment for recurrent ovarian carcinoma after response to platinum therapy (ARIEL3): a randomised, double-blind, placebo-controlled, phase 3 trial. Lancet 2017;390(10106):1949-61.

[74] Zhang Z-Y, Kansra V, van Andel L, Tibben $M$, Rosing $\mathrm{H}$, Lu $\mathrm{S}$, et al. Characterization of absorption, metabolism, and elimination of Niraparib, an investigational poly (ADP-ribose) polymerase inhibitor, in cancer patients. Clin Ther 2017;39(8-suppl):e7-8.

[75] Sandhu SK, Schelman WR, Wilding G, Moreno V, Baird RD, Miranda S, et al. The poly(ADP-ribose) polymerase inhibitor niraparib (MK4827) in BRCA mutation carriers and patients with sporadic cancer: A phase 1 dose-escalation trial. Lancet Oncol 2013;14(9):882-92.

[76] Mirza MR, Monk BJ, Herrstedt J, Oza AM, Mahner S, Redondo A, et al. Niraparib Maintenance Therapy in Platinum-Sensitive, Recurrent Ovarian Cancer. N Engl J Med 2016;375(22):2154-64.

[77] Del Campo JM, Matulonis UA, Malander S, Provencher D, Mahner S, Follana $P$, et al. Niraparib maintenance therapy in patients with recurrent ovarian cancer after a partial response to the last platinum-based chemotherapy in the ENGOT-OV16/NOVA trial. J Clin Oncol 2019;37(32):2968-73.

[78] Jiang X, Li W, Li X, Bai H, Zhang Z. Current status and future prospects of PARP inhibitor clinical trials in ovarian cancer. Cancer Manag Res 2019;11:4371-90.

[79] González-Martín A, Pothuri B, Vergote I, DePont Christensen R, Graybill W, Mirza MR, et al. Niraparib in Patients with Newly Diagnosed Advanced Ovarian Cancer. N Engl J Med 2019;381(25):2391-402.

[80] Moore KN, SecordAA, Geller MA, MillerDS, Cloven $\mathrm{N}$, Fleming GF, et al. Niraparib monotherapy for late-line treatment of ovarian cancer (QUADRA): a multicentre, open-label, single-arm, phase 2 trial. Lancet Oncol 2019;20(5):636-48.

[81] Murai J, Huang SN, Renaud A, Zhang Y, Ji J, Takeda S, et al. Stereospecific PARP trapping by BMN 673 and comparison with olaparib and rucaparib. Mol Cancer Ther 2014;13(2):433-43.

[82] Kizilbash SH, Gupta SK, Chang K, Kawashima R, Parrish KE, Carlson BL, et al. Restricted Delivery of Talazoparib Across the Blood-Brain Barrier Limits the Sensitizing Effects of PARP Inhibition on Temozolomide Therapy in Glioblastoma. Mol Cancer Ther 2017;16(12):2735-46.

[83] Shen Y, Rehman FL, Feng Y, Boshuizen J, Bajrami I, Elliott R, et al. BMN 673, a novel and 
highly potent PARP1/2 inhibitor for the treatment of human cancers with DNA repair deficiency. Clin Cancer Res 2013;19:5003-15.

[84] BMN 673 (Talazoparib), an Oral PARP Inhibitor, in People With Deleterious BRCA1/2 MutationAssociated Ovarian Cancer Who Have Had Prior PARP Inhibitor Treatment. https ://clinicaltrials. gov/ct2/show/NCT02 326844. Accessed 29 Nov 2019.

[85] Nuthalapati S, Munasinghe W, Giranda V, Xiong $\mathrm{H}$. Clinical Pharmacokinetics and Mass Balance of Veliparib in Combination With Temozolomide in Subjects With Nonhematologic Malignancies. Clin Pharmacokinet 2018;57(1):51-8.

[86] Tawbi HAH, Chu E, Lin Y, Hyman DM, Goel S, Rudek MA, et al. Early phase I study of the PARP inhibitor veliparib (ABT-888) alone or in combination with carboplatin/paclitaxel (CP) in patients with varying degrees of hepatic or renal dysfunction: A study of the $\mathrm{NCl}$-Organ Dysfunction Working Group (ODG). J Clin Oncol 2014;32(15_suppl):2572.

[87] Steffensen KD, Adimi P, Jakobsen A. Veliparib monotherapy to patients with BRCA germ line mutation and platinum-resistant or partially platinum-sensitive relapse of epithelial ovarian cancer: A phase I/II study. Int J Gynecol Cancer 2017;27(9):1842-9.

[88] Armstrong DK, Moore KN, Miller A, Bell-McGuinn $\mathrm{KM}$, Schilder RJ, Fracasso PM, et al. A phase I study of veliparib incorporated into front-line platinum based cheotherpy and bevacizumab in epithelial ovarian cancer (NCT00989651): A GOG/ nrg trial. J Clin Oncol 2019;37(15_suppl):5523.

[89] Coleman RL, Sill MW, Bell-Mcguinn K, Aghajanian C, Gray HJ, Tewari KS, et al. A phase II evaluation of the potent, highly selective PARP inhibitor veliparib in the treatment of persistent or recurrent epithelial ovarian, fallopian tube, or primary peritoneal cancer in patients who carry a germline BRCA1 or BRCA2 mutation - An NRG Oncology/Gynecologic Oncology Group study. Gynecol Oncol 2015;137(3):386-91.

[90] Wang L, Yang C, Xie C, Jiang J, Gao M, Fu $L$, et al. Pharmacologic characterization of fluzoparib, a novel poly (ADPribose) polymerase inhibitor undergoing clinical trials. Cancer Sci 2019;110(3):1064-75.

[91] Li H, Liu R, Shao B, Ran R, Song G, Wang K, et al. Phase I dose-escalation and expansion study of the PARP inhibitor, fluzoparib (SHR3162), in patients with advanced solid tumours. Clin J Cancer Res 2020;32(3):370-383.
[92] Gupta SK, Carlson BL, Schroeder MA, Bakken KK, Tuma AC, Sarkaria JN. Inhibition of PARP activity by BGB-290 potentiates efficacy of temozolomide in patient derived xenografts of glioblastoma multiforme. Cancer Res 2015;75 (suppl 15):3505.

[93] Maintenance Treatment With BGB-290 Versus Placebo in Participants With Platinum-sensitive Recurrent Ovarian Cancer. https://clinicaltrials. gov/ct2/show/NCT03519230

[94] Pamiparib in Fusion Positive, Reversion Negative High Grade Serous Ovarian Cancer or Carcinosarcoma With BRCA1/2 Gene Mutations If Progression on Substrate Poly ADP Ribose Polymerase Inhibitbor (PARPI) or Chemotherapy (PRECISE). https://clinicaltrials.gov/ct2/show/ NCT03933761

[95] McGonigle S, Chen Z, Wu J, Chang P, KolberSimonds D, et al. E7449: A dual inhibitor of PARP1/2 and tankyrase1/2 inhibits growth of DNA repair deficient tumors and antagonizes Wnt signaling. Oncotarget. 2015;6(38):41307-23.

[96] Investigation of $2 X-121$ in Patients With Advanced Ovarian Cancer Selected by the $2 X-121$ DRP® (PREDICT 2X-121). https://clinicaltrials.gov/ct2/ show/NCT03878849

[97] Veneris JT, Matulonis UA, Liu JF, Konstantinopoulos PA. Choosing wisely: Selecting PARP inhibitor combinations to promote anti-tumor immune responses beyond BRCA mutations. Gnecol Oncol 2020;156(2):488-97.

[98] Oza AM, Cibula D, Oaknin A, Poole CJ, Mathijssen RHJ, Gabe S, et al. Olaparib plus paclitaxel plus carboplatin $(\mathrm{P} / \mathrm{C})$ followed by olaparib maintenance treatment in patients (pts) with platinum-sensitive recurrent serous ovarian cancer (PSC SOC): A randomized, open-label phase II study. JCO 2012;30(15):5001.

[99] Del Conte G, Sessa C, von Moos R, Vigano L, Digena T, Locatelli A, et al. Phase I study of olaparib in combination with liposomal doxorubicin in patients with advanced solid tumours. BJC 2014;111:651-9.

[100] Perez-Fidalgo JA, Iglesias M, Bohn U, Calvo E, Garcia Y, Guerra E, et al. GEIC01601ROLANDO: a multicentric single arm Phase II clinical trial to evaluate the combination of olaparib and pegylated liposomal doxorubicin for platinum-resistant ovarian cancer. Future Sci OA. 2019;5(2):FSO370.

[101] Rivkin SE, Moon J, Iriarte DS, Bailey E, Sloan HL, Goodman GE, et al. Phase lb with expansion study of olaparib plus weekly (Metronomic) carboplatin 
and paclitaxel in relapsed ovarian cancer patients. Int J Gynecol Cancer 2019;(online).

[102] Dhawan MS, Bartelink IH, Aggarwal RR, Leng J, Zhang JZ, Pawlowska N, et al. Differential Toxicity in Patients with and without DNA Repair Mutations: Phase I Study of Carboplatin and Talazoparib in Advanced Solid Tumors. Clin Cancer Res 2017;23(21):6400-10.

[103] Schafer ES, Rau RE, Berg SL, Liu X, Minard CG, Bishop AJR, et al. Phase 1/2 trial of talazoparib in combination with temozolomide in children and adolescents with refractory/recurrent solid tumors including Ewing sarcoma: A Children's Oncology Group Phase 1 Consortium study (ADVL1411). Pediatr Blood Cancer 2020;67(2):e28073.

[104] Coleman RL, Fleming GF, Brady MF, Swisher EM, Steffensen KD, Friedlander M, et al. Veliparib with first-line chemotherapy and as maintenance therapy in ovarian cancer. $\mathrm{N}$ Engl J Med 2019;381(25):2403-15.

[105] LoRusso PM, Li J, Burger A, Heilbrun LK, Sausville EA, Boerner SA, et al. Phase I safety, pharmacokinetic, and pharmacodynamic study of the poly (ADP-ribose) polymerase (PARP) inhibitor veliparib (ABT-888) in combination with irinotecan in patients with advanced solid tumors. Clin Cancer Res 2016;22:3227-37.

[106] Wahner Hendrickson AE, Menefee ME, Hartmann LC, Long HJ, Northfelt DW, Reid JM, et al. A phase I clinical trial of the poly(ADPribose) polymerase inhibitor veliparib and weekly topotecan in patients with solid tumors. Clin Cancer Res 2018;24(4):744-52.

[107] Hjortkjær M, Kanstrup H, Jakobsen A, Steffensen KD. Veliparib and topotecan for patients with platinum-resistant or partially platinum-sensitive relapse of epithelial ovarian cancer with BRCA negative or unknown BRCA status. Cancer Treat Res Commun 2018;14:7-12.

[108] Gray HJ, Bell-McGuinn K, Fleming GF, Cristea $M$, Xiong $H$, Sullivan $D$, et al. Phase I combination study of the PARP inhibitor veliparib plus carboplatin and gemcitabine in patients with advanced ovarian cancer and other solid malignancies. Gynecol Oncol 2018;148(3):50714.

[109] Keiss KA, Herman JM, Armstrong D, Zahurak M, Fyles A, Brade A, et al. A final report of a phase I study of veliparib (ABT-888) in combination with low-dose fractionated whole abdominal radiation therapy (LDFWAR) in patients with advanced solid malignancies and peritoneal carcinomatosis with a dose escalation in ovarian and fallopian tube cancers. Gynecol Oncol 2017;144(3):486-90.

[110] Liu JF, Tolaney SM, Birrer M, Fleming GF, Buss MK, Dahlberg SE, et al. A Phase 1 trial of the poly(ADP-ribose) polymerase inhibitor olaparib (AZD2281) in combination with the antiangiogenic cediranib (AZD2171) in recurrent epithelial ovarian or triple-negative breast cancer. Eur J Cancer 2013;49(14):2972-8.

[111] Liu JF, Barry WT, Birrer M, Lee JM, Buckanovich RJ, Fleming GF, et al. Combination cediranib and olaparib versus olaparib alone for women with recurrent platinum-sensitive ovarian cancer: A randomised phase 2 study. Lancet Oncol 2014;15(11):1207-14.

[112] Liu JF, Barry WT, Wenham RM, Wahner Hendrickson AE, Armstrong DK, et al. A phase 2 biomarker trial of combination cediranib and Olaparib in relapsed platinum sensitive and platinum resistant ovarian cancer. JCO 2018;36(15_suppl):5519.

[113] Liu JF, Barry WT, Birrer M, Lee JM, Buckanovich RJ, Fleming GF, et al. Overall survival and updated progression-free survival outcomes in a randomized phase II study of combination cediranib and olaparib versus olaparib in relapsed platinum-sensitive ovarian cancer. Ann Oncol 2019;30(4):551-7.

[114] Liu JF, Brady MF, Matulonis UA, Miller A, Kohn EC, Swisher EM, et al. A phase III study comparing single-agent olaparib or the combination of cediranib and olaparib to standard platinum-based chemotherapy in recurrent platinum-sensitive ovarian cancer. JCO 2020;38(15_Suppl):6003.

[115] Ray-Coquard I, Pautier P, Pignata S, Pérol D, González-Martín A, Berger R, et al. Olaparib plus bevacizumab as first-line maintenance in ovarian cancer. N Engl J Med 2019;381(25):2416-28.

[116] Mirza MR, Åvall Lundqvist E, Birrer MJ, dePont Christensen R, Nyvang GB, Malander S, et al. Niraparib plus bevacizumab versus niraparib alone for platinum-sensitive recurrent ovarian cancer (NSGO-AVANOVA2/ENGOT-ov24): a randomised, phase 2, superiority trial. Lancet Oncol 2019;20(10):1409-19.

[117] Drew $Y$, de Jonge $M$, Hong SH, Park YH, Wolfer A, Brown J, et al. An open-label, phase II basket study of olaparib and durvalumab (MEDIOLA): Results in germline-mutated (gBRCAm) platinumsensitive relapsed (PSR) ovarian cancer (OC). Gynecol Oncol 2018;149(Suppl 1):246-7.

[118] Lampert EJ, Zimmer A, Padget M, CiminoMathews A, Nair JR, Liu Y, et al. Combination 
of PARP Inhibitor Olaparib, and PD-L1 Inhibitor Durvalumab, in Recurrent Ovarian Cancer: a Proof-of-Concept Phase II Study. Clin Cancer Res 2020;26(16):4268-79.

[119] Konstantinopoulos PA, Waggoner S, Vidal GA, Mita M, Moroney JW, Holloway R, et al. Single-Arm Phases 1 and 2 Trial of Niraparib in Combination with Pembrolizumab in Patients with Recurrent Platinum-Resistant Ovarian Carcinoma. JAMA Oncol 2019;5(8):1141-9.

[120] Eskander RN, Ledermann JA, Birrer MJ, Fujiwara K, Gaillard S, Richardson E, et al. JAVELIN ovarian PARP 100 study design: Phase III trial of avelumab + chemotherapy followed by avelumab + talazoparib maintenance in previously untreated epithelial ovarian cancer. JCO 2019;37(8_Suppl).

[121] Farley J, Brady WE, Vathipadiekal V, Lankes HA, Coleman R, Morgan MA, et al. Selumetinib in women with recurrent low-grade serous carcinoma of the ovary or peritoneum: an openlabel, single-arm, phase 2 study. Lancet Oncol 2013;14(2):134-40.

[122] Hew KE, Miller PC, El-Ashry D, Sun J, Besser $\mathrm{AH}$, Ince TA, et al. MAPK Activation Predicts Poor Outcome and the MEK Inhibitor, Selumetinib, Reverses Antiestrogen Resistance in ER-Positive High-Grade Serous Ovarian Cancer. Clin Cancer Res 2016;22(4):935-47.

[123] Konstantinopoulos PA, Barry WT, Birrer M, Westin SN, Cadoo KA, Shapiro GI, et al. Olaparib and $\alpha$-specific PI3K inhibitor alpelisib for patients with epithelial ovarian cancer: a dose-escalation and dose-expansion phase $1 \mathrm{~b}$ trial. Lancet Oncol 2019;20(4):570-80.

[124] Gupta GV, Fernandez YL, Roby K, Pathak $\mathrm{H}$, Hirst J, Wilson AJ, et al. Entinostat enhances the efficacy of olaparib in preclinical models of ovarian cancer. Cancer Res 2019;(79)(13 Suppl) (Abstract 3501).

[125] Pulliam N, Fang F, Ozes AR, Tang J, Adewuyi $A$, Keer $\mathrm{H}$, et al. An Effective Epigenetic-PARP Inhibitor Combination Therapy for Breast and Ovarian Cancers Independent of BRCA Mutations. Clin Cancer Res 2018;24(13):316375.

[126] D' Andrea AD. Mechanisms of PARP inhibitor sensitivity and resistance. DNA Repair (Amst) 2018;71:172-6.

[127] Drost R, Bouwman P, Rottenberg S, Boon U, Schut E, Klarenbeek S, et al. BRCA1 RING function is essential for tumor suppression but dispensable for therapy resistance. Cancer Cell 2011;20(6):797-809.
[128] Johnson N, Johnson SF, Yao W, Li YC, Choi YE, Bernhardy AJ, et al. Stabilization of mutant BRCA1 protein confers PARP inhibitor and platinum resistance. Proc Natl Acad Sci U S A. 2013;110(42):17041-6.

[129] Sakai W, Swisher EM, Karlan BY, Agarwal MK, Higgins J, Friedman C, et al. Secondary mutations as a mechanism of cisplatin resistance in BRCA2mutated cancers. Nature 2008;451(7182):111620.

[130] Edwards SL, Brough R, Lord CJ, Natrajan R, Vatcheva $R$, Levine $D A$, et al. Resistance to therapy caused by intragenic deletion in BRCA2. Nature 2008;451(7182):1111-5.

[131] Quigley D, Alumkal JJ, Wyatt AW, Kothari V, Foye A, Lloyd $P$, et al. Analysis of circulating cell-free DnA identifies multiclonal heterogeneity of BRCA2 reversion mutations associated with resistance to PARP inhibitors. Cancer Discov 2017;7(9):999-1005.

[132] Pettitt SJ, Krastev DB, Brandsma I, Dréan A, Song F, Aleksandrov R, et al. Genome-wide and high-density CRISPR-Cas9 screens identify point mutations in PARP1 causing PARP inhibitor resistance. Nat Commun 2018;9(1):1849.

[133] Chapman JR, Barral P, Vannier JB, Borel V, Steger M, Tomas-Loba A, et al. RIF1 Is Essential for 53BP1-Dependent Nonhomologous End Joining and Suppression of DNA Double-Strand Break Resection. Mol Cell 2013;49(5):858-71.

[134] Bouwman P, Aly A, Escandell JM, Pieterse M, Bartkova J, van der Gulden H, et al. 53BP1 loss rescues BRCA1 deficiency and is associated with triple-negative and BRCA-mutated breast cancers. Nat Struct Mol Biol 2010;17(6):688-95.

[135] Gupta R, Somyajit K, Narita T, Maskey E, Stanlie A, Kremer M, et al. DNA Repair Network Analysis Reveals Shieldin as a Key Regulator of NHEJ and PARP Inhibitor Sensitivity. Cell 2018;173(4):972988.e23.

[136] Choi YH, Yu AM. ABC transporters in multidrug resistance and pharmacokinetics, and strategies for drug development. Curr Pharm Des 2014;20(5):793-807.

[137] Schlacher K, Wu H, Jasin M. A distinct replication fork protection pathway connects Fanconi anemia tumor suppressors to RAD51-BRCA1/2. Cancer Cell 2012;22(1):106-16.

[138] Lomonosov M, Anand S, Sangrithi M, Davies $R$, Venkitaraman AR. Stabilization of stalled DNA replication forks by the BRCA2 breast cancer susceptibility protein. Genes Dev. 2003;17(24):3017-22. 
[139] Ray Chaudhuri A, Callen E, Ding X, Gogola E, Duarte AA, Lee JE, et al. Replication fork stability confers chemoresistance in BRCA-deficient cells. Nature 2016;535(7612):382-7.

[140] Rondinelli B, Gogola E, Yücel H, Duarte AA, van de Ven $M$, van der Sluijs $R$, et al. EZH2 promotes degradation of stalled replication forks by recruiting MUS81 through histone H3 trimethylation. Nat Cell Biol 2017;19(11):1371-8.

[141] Gallyas F Jr, Sumegi B, Szabo C. Role of Akt Activation in PARP Inhibitor Resistance in Cancer. Cancers (Basel). 2020;12(3):532.

[142] Aguilar-Quesada R, Muñoz-Gámez JA, MartínOliva D, Peralta A, Valenzuela MT, MatínezRomero $\mathrm{R}$, et al. Interaction between ATM and PARP-1 in response to DNA damage and sensitization of ATM deficient cells through PARP inhibition. BMC Mol Biol 2007;8:29.

[143] Tapodi A, Bognar Z, Szabo C, Gallyas F, Sumegi B, Hocsak E. PARP inhibition induces Aktmediated cytoprotective effects through the formation of a mitochondria-targeted phosphoATM-NEMO-Akt-mTOR signalosome. Biochem Pharmacol 2019;162:98-108.

[144] Staropoli N, Ciliberto D, Del Giudice T, luliano E, Cucè M, Grillone F, et al. The Era of PARP inhibitors in ovarian cancer: "Class Action" or not? A systematic review and meta-analysis. Crit Rev Oncol Hematol 2018;131:83-9.

[145] Madariaga A, Bowering V, Ahrari S, Oza AM, Lheureux S. Manage wisely: poly (ADPribose) polymerase inhibitor (PARPi) treatment and adverse events. Int J Gynecol Cancer 2020;30(7):903-15.

[146] Liu Y, Meng J, Wang G. Risk of selected gastrointestinal toxicities associated with poly (ADP-ribose) polymerase (PARP) inhibitors in the treatment of ovarian cancer: a metaanalysis of published trials. Drug Des Devel Ther 2018;12:3013-9.

[147] Zhou JX, Feng LJ, Zhang X. Risk of severe hematologic toxicities in cancer patients treated with PARP inhibitors: a meta-analysis of randomized controlled trials. Drug Des Devel Ther 2017;11:3009-17.

[148] Zibetti Dal Molin G, Westin SN, Msaouel P, Gomes LM, Dickens A, Coleman RL. Discrepancy in calculated and measured glomerular filtration rates in patients treated with PARP inhibitors. Int J Gynecol Cancer 2020;30(1):89-93.
[149] Ison G, Howie LJ, Amiri-Kordestani L, Zhang L, Tang S, Sridhara R, et al. FDAApproval Summary: Niraparib for the Maintenance Treatment of Patients with Recurrent Ovarian Cancer in Response to Platinum-Based Chemotherapy. Clin Cancer Res 2018;24(17):4066-71. 